\title{
Celiac disease: a comprehensive current review
}

\author{
Giacomo Caio ${ }^{1,2^{*}+}$ (D) Umberto Volta ${ }^{3 \dagger}$, Anna Sapone ${ }^{2,4}$, Daniel A. Leffler ${ }^{4,5}$, Roberto De Giorgio ${ }^{1}$, \\ Carlo Catassi ${ }^{2,6+}$ and Alessio Fasano ${ }^{2+}$
}

\begin{abstract}
Background: Celiac disease remains a challenging condition because of a steady increase in knowledge tackling its pathophysiology, diagnosis, management, and possible therapeutic options.

Main body: A major milestone in the history of celiac disease was the identification of tissue transglutaminase as the autoantigen, thereby confirming the autoimmune nature of this disorder. A genetic background (HLA-DQ2/DQ8 positivity and non-HLA genes) is a mandatory determinant of the development of the disease, which occurs with the contribution of environmental factors (e.g., viral infections and dysbiosis of gut microbiota). Its prevalence in the general population is of approximately $1 \%$, with female predominance. The disease can occur at any age, with a variety of symptoms/manifestations. This multifaceted clinical presentation leads to several phenotypes, i.e., gastrointestinal, extraintestinal, subclinical, potential, seronegative, non-responsive, and refractory. Although small intestinal biopsy remains the diagnostic 'gold standard', highly sensitive and specific serological tests, such as tissue transglutaminase, endomysial and deamidated gliadin peptide antibodies, have become gradually more important in the diagnostic work-up of celiac disease. Currently, the only treatment for celiac disease is a life-long, strict gluten-free diet leading to improvement in quality of life, ameliorating symptoms, and preventing the occurrence of refractory celiac disease, ulcerative jejunoileitis, and small intestinal adenocarcinoma and lymphoma.
\end{abstract}

Conclusions: The present review is timely and provides a thorough appraisal of various aspects characterizing celiac disease. Remaining challenges include obtaining a better understanding of still-unclear phenotypes such as slow-responsive, potential (minimal lesions) and seronegative celiac disease. The identification of alternative or complementary treatments to the gluten-free diet brings hope for patients unavoidably burdened by diet restrictions.

Keywords: Alternative treatment, Clinical phenotypes, Epidemiology, Genetics, Gluten-free diet, Histopathological findings, Pathogenesis, Serological markers

\section{Introduction}

Celiac disease $(\mathrm{CD})$ is an autoimmune condition characterized by a specific serological and histological profile triggered by gluten ingestion in genetically predisposed individuals [1]. Gluten is the general term for alcoholsoluble proteins present in various cereals, including wheat, rye, barley, spelt, and kamut [1]. In recent years,

\footnotetext{
*Correspondence: caigmp@unife.it

${ }^{\dagger}$ Giacomo Caio and Umberto Volta these authors share co-first authorship. Carlo Catassi and Alessio Fasano these authors share co-last authorship. 'Department of Medical Sciences, University of Ferrara, Via Aldo Moro 8, Cona, 44124 Ferrara, Italy

${ }^{2}$ Center for Celiac Research and Treatment, Massachusetts General Hospital, Boston, MA 02114, USA

Full list of author information is available at the end of the article
}

there have been significant changes in the diagnosis, pathogenesis, and natural history of this condition [2], with $\mathrm{CD}$ undergoing a true 'metamorphosis' due to the steady increase in the number of diagnoses identified, even in geriatric patients [2]. This has been mainly attributed to the greater availability of sensitive and specific screening tests, which allow identification of the risk groups for $\mathrm{CD}$ and led to a significant raise in diagnoses worldwide [2-5]. Several theories have suggested that the globalization and ubiquitous spread of 'false' or 'extreme' versions of the Mediterranean diet including the consumption of very high quantities of gluten (up to $20 \mathrm{~g} /$ day), has led to an increased prevalence and incidence of $\mathrm{CD}[3,4]$. In addition, the quality of gluten 
itself might also play a contributory role. Indeed, the production of new grain variants due to technological rather than nutritional reasons may have influenced the observed increase in the number of $C D$ diagnoses in recent years $[4,5]$. However, these hypotheses have not been confirmed and the real cause of the risk in CD diagnoses remains unknown. Furthermore, the epidemiological observation that similar 'epidemics' are reported for other autoimmune diseases in the Western hemisphere [6] suggests that environmental factors other than gluten can be at play.

In this article, we aimed to provide a thorough review on the multifaceted features of $\mathrm{CD}$ spanning from its epidemiological, pathogenetic, clinical, and diagnostic aspects to therapeutic strategies using a practical approach in order to help general practitioners, internal medicine physicians, and gastroenterologists in their clinical practice.

\section{Epidemiology}

$\mathrm{CD}$ is one of the most common autoimmune disorders, with a reported prevalence of $0.5-1 \%$ of the general population (Table 1), with the exception of areas showing low frequency of $\mathrm{CD}$-predisposing genes and low gluten consumption (e.g., sub-Saharan Africa and Japan) [7-13]. Studies have shown that most CD cases remain undetected in the absence of serological screening due to heterogeneous symptoms and/or poor disease awareness. CD prevalence is increasing in Western countries. Between the years 1975 and 2000, CD prevalence increased 5-fold in the US, for reasons that are currently unknown [14]. The prevalence of CD is higher in firstdegree CD relatives (10-15\%) and in other at-risk groups, particularly patients with Down syndrome, type 1 diabetes, or IgA deficiency [1].

\section{Pathophysiology}

$\mathrm{CD}$ is a unique autoimmune disease in that its key genetic elements (human leukocyte antigen (HLA)-DQ2 and HLA-DQ8), the auto-antigen involved (tissue transglutaminase (tTG)), and the environmental trigger (gluten) are all well defined. A major drawback in $C D$ research has been the lack of a reliable and reproducible animal model, with the possible exception of the Irish setter dog, which may develop a gluten-related disease [15]. Nevertheless, new technologies pertinent to human gut biology and immunology are opening unprecedented opportunities for major research breakthroughs.

As with many other autoimmune diseases, we have witnessed an epidemic of $\mathrm{CD}$, questioning the previous paradigm that gluten is the only key element dictating the onset of the disease in genetically at-risk subjects. Improved hygiene and lack of exposure to various microorganisms also have been linked with a steep increase in autoimmune disorders in industrialized countries during the past 40 years $[1,16]$. The hygiene hypothesis argues that the rising incidence of many autoimmune diseases may partially be the result of lifestyle and environmental changes that have reduced our exposure to pathogens. With breakthroughs in the role of the gut microbiological ecosystem [17] in dictating the balance between tolerance and immune response leading to autoimmunity, this hypothesis is under scrutiny. Regardless of whether autoimmune diseases are due to too much or too little exposure to microorganisms, it is generally accepted that adaptive immunity and imbalance between $\mathrm{T}$ helper 1 and 2 cell responses are key elements of the pathogenesis of the autoimmune process. Besides genetic predisposition and exposure to gluten, loss of intestinal barrier function, a pro-inflammatory innate immune response triggered by gluten, inappropriate adaptive immune response, and an imbalanced gut microbiome all seem to be key 'ingredients' of the $C D$ autoimmunity recipe.

\section{Genetics}

As with any other autoimmune disease, CD has a strong hereditary component as testified by its high familial recurrence $(\sim 10-15 \%)$ and the high concordance of the disease among monozygotic twins (75-80\%) [18]. Also common to other autoimmune diseases is the relevant role of HLA class II heterodimers, specifically DQ2 and DQ8, in the heritability of CD. HLA-DQ2 homozygosis confers a much higher risk (25-30\%) of developing

Table 1 Serological screening for celiac disease in adults (confirmed with duodenal biopsy) in the general population

\begin{tabular}{|c|c|c|c|c|c|}
\hline & First level antibody test & No. of cases & Age, years & Country & Prevalence of celiac disease \\
\hline Corazza et al., 1997 [6] & $E m A$ & 2237 & $20-87$ & Italy & $0.18 \%$ \\
\hline Ivarsson et al., 1999 [7] & EmA & 1894 & $25-74$ & Sweden & $0.53 \%$ \\
\hline Riestra et al., 2000 [8] & EmA & 1170 & $14-89$ & Spain & $0.26 \%$ \\
\hline Volta et al., 2001 [9] & EmA & 3483 & $14-65$ & Italy & $0.57 \%$ \\
\hline Mustalahti et al., 2010 [10] & Anti-tTG, EmA & 6403 & 30-93 & Finland & $2.5 \%$ \\
\hline Rubio-Tapia et al., 2012 [11] & Anti-tTG, EmA & 7798 & $23-66$ & USA & $0.71 \%$ \\
\hline Singh et al., 2016 [12] & Anti-tTG, EmA & 43,955 & Not specified & Asia & $0.5 \%$ \\
\hline
\end{tabular}

Anti-tTG anti-transglutaminase antibodies, EmA anti-endomysium antibodies 
early-onset $C D$ in infants with a first-degree family member affected by the disease [19-21]. Since HLADQ2/HLA-DQ8 is frequent among the general population (25-35\%), and only $3 \%$ of these HLAcompatible individuals will go on to develop CD [22], it is not surprising that genome-wide association studies have identified more than 100 non-HLA-related genes associated with CD $[18,23]$. The relevance of these additional genes in conferring genetic risk for $\mathrm{CD}$ is rather limited, but they may lead to the discovery of key pathways potentially involved in disease pathogenesis.

\section{Gluten as an environmental trigger of $C D$}

Introduced 10,000 years ago during the transition from a nomadic lifestyle to agricultural settlements, gluten-containing grains are a recent addition to the human diet. Moreover, gluten is one of the few digestion-resistant proteins consumed chronically in significant quantities and is constituted by several non-digestible immunogenic peptides. These two characteristics could help in breaking the tolerance to this food antigen, when the immune system is activated, as can happen during an enteric infection. Gliadins, key components of gluten, are complex proteins unusually rich in prolines and glutamines and are not completely digestible by intestinal enzymes [24]. The final product of this partial digestion is a mix of peptides that can trigger host responses (increased gut permeability and innate and adaptive immune response) that closely resemble those instigated by the exposure to potentially harmful microorganisms [25-28].

\section{Gluten trafficking from lumen to lamina propria (paracellular and transcellular)}

Studies from our group and others have shown that gliadin can cause an immediate and transient increase in intercellular tight junction permeability of intestinal epithelial cells [23, 24] (Fig. 1). This effect has been linked to the release of zonulin, a family of molecules that increases paracellular permeability by causing tight junction disassembly [29-31]. Gliadin enhances zonulin-dependent increased gut paracellular permeability irrespective of disease status [32-39]. Similarly, when tested in C57BL/6 mice duodenal tissues, gliadin caused a myeloid differentiation primary response 88-dependent increase in gut mucosa permeability [40]. We have also identified two alpha-gliadin motifs that can modulate the intestinal barrier function by binding to chemokine receptor 3 , with subsequent zonulin release that causes disassembly of the interepithelial tight junction complex [41]. The involvement of the paracellular pathway for gluten trafficking in the lamina propria has also been corroborated by genetic studies identifying an association of some tight junction genes with CD [42-44]. There is solid evidence that gluten can also cross the intestinal barrier through the transcellular pathway once tolerance to gluten has been broken $[45,46]$. The transferrin receptor CD71, normally expressed on the basolateral side of enterocytes, is overexpressed on the luminal side of the intestinal epithelium in CD patients during the acute phase of the disease, leading to an apical-to-basal retrotranscytosis of gliadin peptides complexed with secretory IgA [47]. This retrotranscytosis of secretory IgA-gliadin complexes protects gliadin fragments from lysosomal degradation and promotes the entry of harmful gliadin peptides into the intestinal lamina propria [47], thereby perpetuating intestinal inflammation initiated by the paracellular passage of these peptides (Fig. 1). Because of their resistance, the gluten immunogenic peptides (GIP) can cross the defective epithelial lining, reach the blood stream (thus extending the inflammatory process), and finally be excreted with the urine [48].

\section{The innate immune response}

Innate immunity plays a critical role in initiating $\mathrm{CD}$, and cytokines such as interleukin (IL)-15 and interferon $\alpha$ can prime the innate immune response by polarizing dendritic cells and intraepithelial lymphocyte function [49]. Recent results suggest that specific gliadin peptides may induce epithelial growth factor and an IL-15dependent proliferation of enterocytes, structural modifications, vesicular trafficking alterations, signaling and proliferation, and stress/innate immunity activation [50]. Alpha-amylase/trypsin inhibitors - molecules conferring pest resistance in wheat - also seem to play a key role in $\mathrm{CD}$ innate immune response by engaging the Toll-like receptor 4-MD2-CD14 complex with subsequent upregulation of maturation markers and release of proinflammatory cytokines in cells from CD patients [51]. These mucosal events, along with the functional breach of epithelial barrier function secondary to the gliadinmediated zonulin release [29-36], the subsequent access of toxic peptides in the lamina propria, and gliadininduced production of high levels of the neutrophilactivating and chemoattractant chemokine IL-8 [26, 52], cause the 'perfect storm' to initiate $\mathrm{CD}$ enteropathy (Fig. 1). More recently, our group showed that gliadin exerts a direct neutrophil chemoattractant effect by interacting with fMet-Leu-Phe receptor $1[53,54]$.

\section{The adaptive immune response}

The erroneous adaptive immune response consequence of a highly specific interplay between selected gluten peptides and major histocompatibility complex class II HLA-DQ2/8-antigen restricted $T$ cells plays a paramount role in CD pathogenesis [55]. Dependent on the post-translational deamidation of gluten peptides by transglutaminase 2 (TG2), this interplay is influenced by 


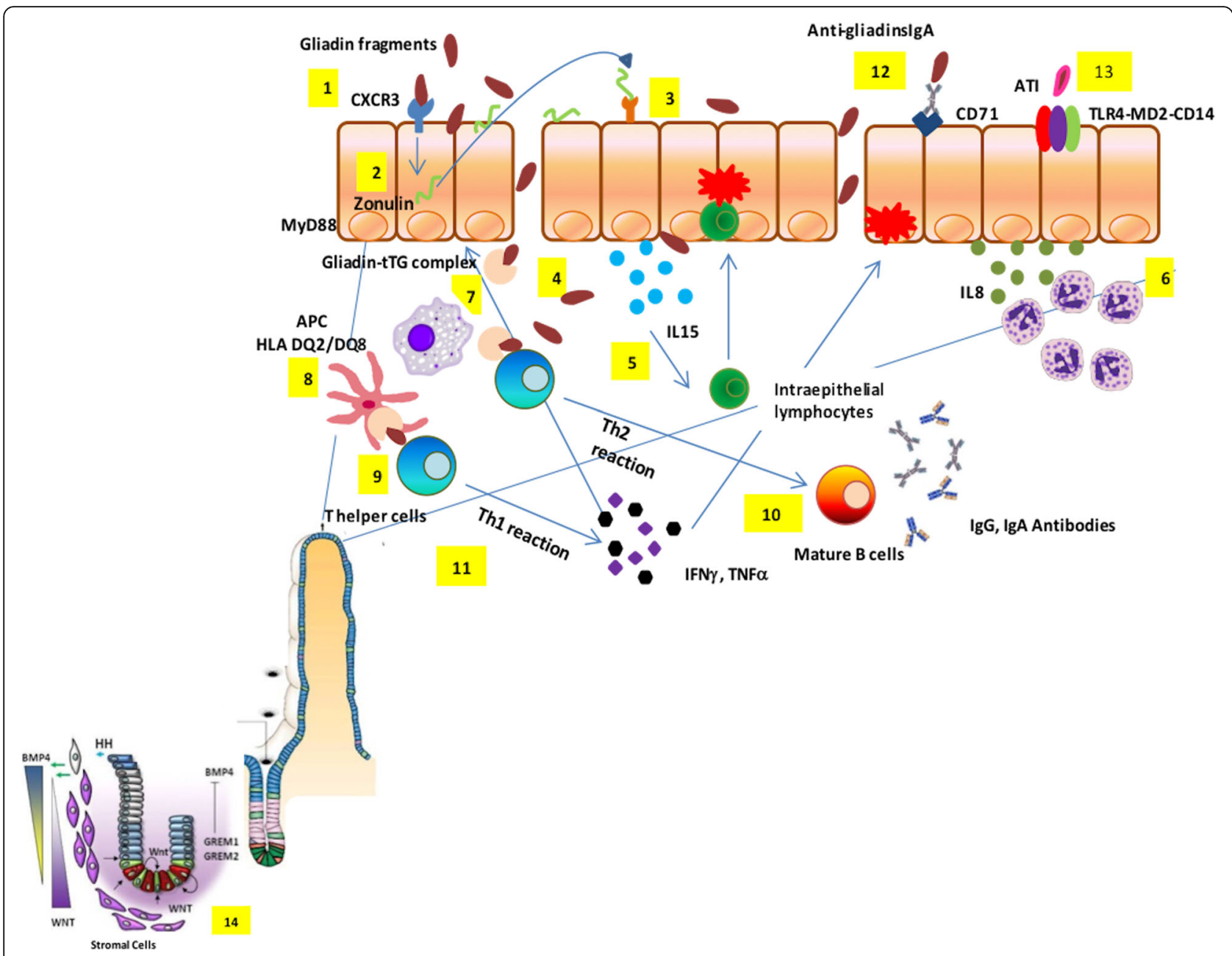

Fig. 1 Celiac disease pathogenesis. Partially digested gliadin fragments interact with chemokine receptor 3 on the apical side of epithelium (1) inducing a myeloid differentiation primary response 88-dependent release of zonulin (2). Zonulin interacts with the intestinal epithelium and triggers increased intestinal permeability (3). Functional loss of the gut barrier facilitates gliadin peptide translocation from lumen to the lamina propria (4). Gliadin peptides trigger release of IL-15, keratinocyte growth factor, and IL-8 (5), with consequent recruitment of neutrophils in the lamina propria (6). Simultaneously, alpha-amylase/trypsin inhibitors engage the Toll like receptor 4-MD2-CD14 complex with subsequent upregulation of maturation markers and release of proinflammatory cytokines (7). Following innate immune-mediated apoptosis of intestinal cells with subsequent release of intracellular tissue transglutaminase, gliadin peptides are partially deamidated (8). Deamidated gliadin is recognized by DQ2/8 $8^{+}$antigen presenting cells (9) and then presented to T helper cells (10). T helper cells trigger activation and maturation of B cells, producing IgM, IgG, and IgA antibodies against tissue transglutaminase (11). T helper cells also produce pro-inflammatory cytokines (interferon $\gamma$ and tumor necrosis factor a) (12), which in turn further increase gut permeability and, together with T killer cells, initiate the enteropathy. Damaged enterocytes express CD71 transporter also on their apical side, resulting in retrotranscytosis of secretory lgA-gliadin complexes (13), thus potentiating gluten trafficking from gut lumen to lamina propria. Ultimately, the interaction between CD4 ${ }^{+} \mathrm{T}$ cells in the lamina propria with gliadin induces their activation and proliferation, with production of proinflammatory cytokines, metalloproteases, and keratinocyte growth factor by stromal cells, which induces crypt hyperplasia and villous blunting secondary to intestinal epithelial cell death induced by intraepithelial lymphocytes. The hyperplastic crypts (14) are characterized by an expansion of the immature progenitor cells compartment (WNT) and downregulation of the Hedgehog signaling cascade. An increased number of stromal cells known to be part of the intestinal stem cell niche and increased levels of bone morphogenetic protein antagonists, like Gremlin-1 and Gremlin-2, may further contribute to the crypt hyperplasia present in celiac disease

the initial imprinting of the innate immune system through IL-15 upregulation that promotes the $\mathrm{CD} 4^{+} \mathrm{T}$ cell adaptive immune response $[56,57]$. Presentation of gluten to $\mathrm{CD}^{+}{ }^{+} \mathrm{T}$ cells carried out by dendritic cells as well as macrophages, B cells, and even enterocytes expressing HLA class II, can cause their recirculation in the lamina propria [58]. The contact of $\mathrm{CD}^{+} \mathrm{T}$ cells in the lamina propria with gluten induces their activation and proliferation, with production of proinflammatory cytokines, metalloproteases, and keratinocyte growth factor by stromal cells, which induces cryptal hyperplasia and villous blunting secondary to intestinal epithelial cell 
death induced by intraepithelial lymphocytes (IELs) [58]. Additionally, there is an overexpression of membranebound IL-15 on enterocytes in active CD causing overexpression of the natural killer (NK) receptors CD94 and NKG2D by $\mathrm{CD}^{+}$IELs [59]. CD crypt hyperplasia has been hypothesized to be the consequence of an imbalance between continuous tissue damage due to the mucosal autoimmune insult described above and inability of the stem cells to compensate. We have recently provided a more mechanistic, evidence-based explanation for hyperplastic crypts in active $\mathrm{CD}$ by showing that the celiac hyperplastic crypt is characterized by an expansion of the immature progenitor cell compartment and downregulation of the Hedgehog signaling cascade [60]. These data shed light on the molecular mechanisms underlying $\mathrm{CD}$ histopathology and illuminate the reason for the lack of enteropathy in the mouse models for CD. Indeed, lack of consistent CD-like enteropathy in humanized mice [61] supports the concept that the accelerated disruption of enterocytes secondary to the adaptive $\mathrm{CD}^{+} \mathrm{T}$ cell insult cannot fully explain $\mathrm{CD}$ pathogenesis, supporting the notion that an intrinsic defect of the stem cell compartment in subjects at risk of $\mathrm{CD}$ is a key element of $\mathrm{CD}$ enteropathy $[60,62]$.

\section{The role of the gut microbiome in the pathogenesis of CD}

In Western countries, a rise in the overall prevalence of $\mathrm{CD}$ has been well documented, but the reasons for this 'epidemic' remain elusive. The combination of epidemiological, clinical, and animal studies suggests that broad exposure to a wealth of commensal, non-pathogenic microorganisms early in life are associated with protection against CD and that pre-, peri-, and post-natal environmental factors may strongly influence the gut ecosystem [17]. Therefore, the hygiene hypothesis concept can be misleading, while an 'environment-dependent dysbiosis hypothesis' would more closely reflect the interplay between host and environmental pressure dictating the balance between health and disease. Several studies have shown an association between $\mathrm{CD}$ and a change in the microbiome composition [63, 64]. However, these associative studies do not necessarily imply causation between microbiota composition and $\mathrm{CD}$ pathogenesis. Many environmental factors known to influence the composition of the intestinal microbiota are also thought to play a role in the development of $\mathrm{CD}[19,21]$.

It has been reported that, compared to control infants, neonates at family risk of $\mathrm{CD}$ had a decreased representation of Bacteriodetes and a higher abundance of Firmicutes [65]. This study also showed that infants who developed autoimmunity had decreased lactate signals in their stools coincident with a diminished representation in Lactobacillus species in their microbiome, which preceded the first detection of positive antibodies [65]. Early microbiota alterations in infants were also suggested in a recent study comparing microbial communities between $\mathrm{DQ}^{+}$and $\mathrm{DQ}^{-}$infants [66]. However, to move from association to causation, large-scale, longitudinal studies are necessary to define if and how gut microbiota composition and metabolomic profiles may influence the loss of gluten tolerance and subsequent onset of $\mathrm{CD}$ in genetically susceptible subjects.

\section{Clinical presentation}

$\mathrm{CD}$ is diagnosed more frequently in women with a female-to-male ratio ranging from 2:1 to 3:1 [1, 2]. However, based on serological screening, the actual femaleto-male ratio is 1.5:1 [67]. The disease can occur at any age from early childhood to the elderly, with two peaks of onset - one shortly after weaning with gluten in the first 2 years of life, and the other in the second or third decades of life. The diagnosis of $\mathrm{CD}$ can be challenging since symptoms can vary significantly from patient to patient [68].

In 2011, the Oslo classification of $\mathrm{CD}$ identified the following clinical presentations: classic, non-classic, subclinical, potential and refractory [69]. Instead of the 'classic/non-classic' categorization, which does not fully reflect current clinical presentations, in this review, we will use a more practical terminology, i.e., intestinal/extraintestinal. These two terms better represent the main clinical phenotypes of $\mathrm{CD}$, which may occur individually (i.e., intestinal vs. extraintestinal) or in combination [70].

The intestinal form of $\mathrm{CD}$ is more commonly detected in the pediatric population and children younger than 3 years and is characterized by diarrhea, loss of appetite, abdominal distention, and failure to thrive [71]. Older children and adults may complain of diarrhea, bloating, constipation, abdominal pain, or weight loss [72]. Nonetheless, in adults, the malabsorption syndrome with chronic diarrhea, weight loss and significant asthenia is quite rare. Despite its uncommon detection, this phenotype can cause hospitalization due to cachexia, sarcopenia, significant hypoalbuminemia, and electrolyte abnormalities. Conversely, an irritable bowel syndrome (IBS)-like presentation with constipation or alternating bowel and/or dyspepsia-like symptoms, such as nausea and sometimes vomiting, is more frequent [2].

Extraintestinal symptoms are common in both children and adults $[2,72]$. They include iron deficiency microcytic anemia, detectable in up to $40 \%$ of cases (by cause of iron malabsorption or chronic inflammation) [73] or, more rarely, macrocytic anemia due to folic acid and/or vitamin B12 deficiency (more frequent in Europe than in the US). Changes in bone mineral density, including osteopenia or osteoporosis (affecting about 70\% of patients at diagnosis), are related to altered absorption 
of calcium and vitamin D3 [74]. In children, growth retardation and short stature can raise the suspect of an underlying $\mathrm{CD}$. Other signs include tooth enamel defects, aphthous stomatitis (identified in about $20 \%$ of undiagnosed CD patients) [75], and hypertransaminasemia (40-50\% of untreated patients), which can be ascribed to food and bacterial antigen translocation reaching the liver due to increased intestinal permeability [76]. A wide array of neurological symptoms, such as headache, paresthesia, neuroinflammation, anxiety and depression, can be detectable in $\mathrm{CD}$ patients. The clinical presentation may also include changes in reproductive function characterized by late menarche, amenorrhea, recurrent miscarriages, premature birth, early menopause, and changes in the number and mobility of spermatozoa. Notably, these manifestations can be reversed when patients start a strict gluten-free diet (GFD), although fatigue and some neurological manifestation as well as functional gastrointestinal (GI) symptoms can persist for a long period in a subgroup of CD patients [2, 77-81].

The subclinical form includes patients with symptoms/signs below the clinical identification threshold and are often recognizable only after the appreciation of the beneficial effects induced by the GFD. A typical example of subclinical cases are those patients undergoing antibody screening due to being relatives of $\mathrm{CD}$ patients or cases identified as a result of a screening strategy in the general population $[2,69]$. The prevalence of various $\mathrm{CD}$ clinical phenotypes observed in our experience is reported in Fig. 2.

$\mathrm{CD}$ can be associated with different autoimmune and idiopathic diseases, including dermatitis herpetiformis (which, as a single manifestation, should prompt testing for $\mathrm{CD}$ ), type 1 diabetes mellitus, Hashimoto's thyroiditis, selective IgA deficiency, alopecia areata, Addison's disease, connective tissue diseases (mainly Sjogren's syndrome), chromosomal diseases (Down, Turner, and William's syndromes), neurological diseases (cerebellar ataxia, peripheral neuropathy, epilepsy with and without occipital calcifications), hepatic autoimmune diseases (primary biliary cholangitis, autoimmune hepatitis, primary sclerosing cholangitis), and idiopathic dilated cardiomyopathy (Table 2) [2, 82-93]. The importance of diagnosing $\mathrm{CD}$ associated with these concomitant diseases is twofold since a GFD is able to resolve symptoms, prevent complications, and improve some of the $\mathrm{CD}$ associated diseases [2].

The potential form of $\mathrm{CD}$ is characterized by positive serological and genetic markers with a normal intestinal mucosa and minimal signs of inflammation such an increase in IELs [69]. Patients with the potential form can manifest with classic and non-classic symptoms or be entirely asymptomatic. The scientific community has not universally agreed on whether or not a GFD should be prescribed for patients with potential CD.

Finally, refractory CD (RCD) is characterized by persistent symptoms and atrophy of the intestinal villi after at least 12 months of a strict GFD. RCD can lead to complications such as ulcerative jejunoileitis, collagenous sprue, and intestinal lymphoma [69].

In recent years, other forms of $\mathrm{CD}$ (not included in the Oslo Classification [69]), i.e., seronegative and GFD non-responsive $\mathrm{CD}$, have been identified in the clinical practice. The seronegative form is characterized by the

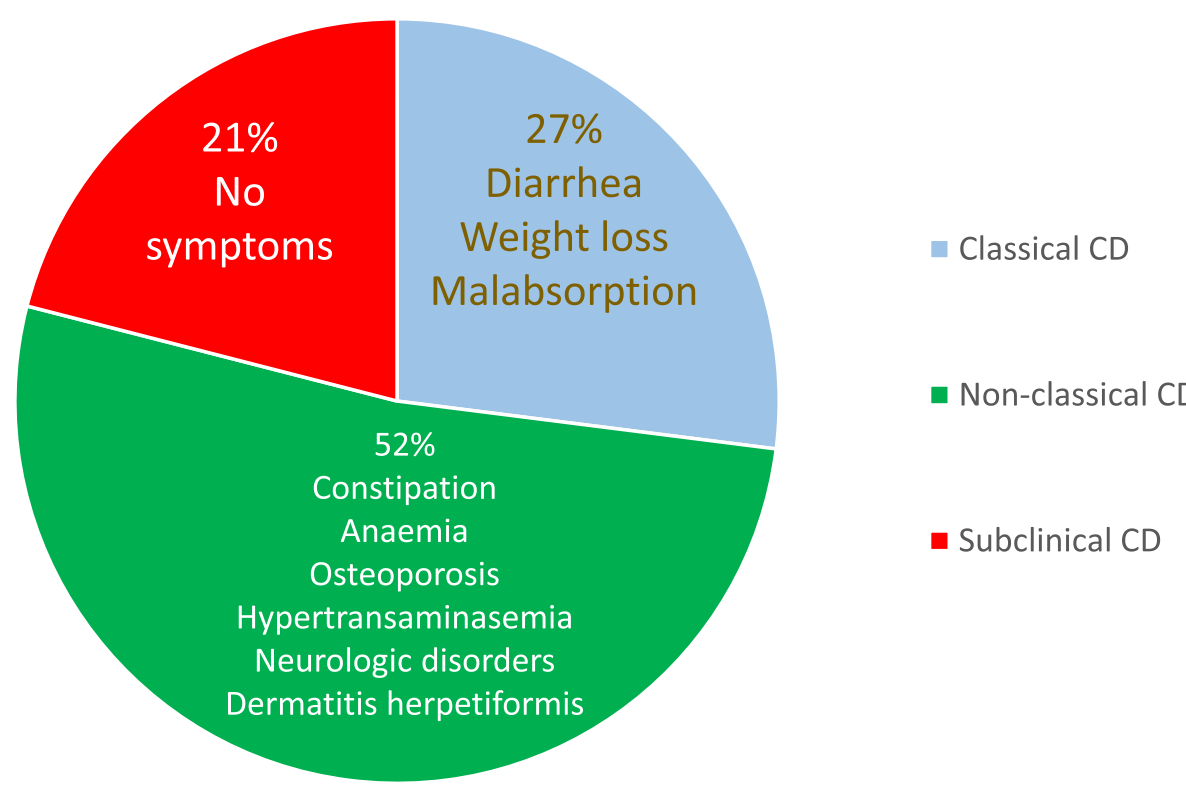

Fig. 2 Prevalence of clinical phenotypes of adult celiac disease in our experience 
Table 2 Diseases associated with celiac disease

\begin{tabular}{|c|c|c|}
\hline Autoimmune & Idiopathic & Chromosomal \\
\hline $\begin{array}{l}\text { Type } 1 \text { diabetes } \\
\text { mellitus }\end{array}$ & Dilated cardiomyopathy & $\begin{array}{l}\text { Down } \\
\text { syndrome }\end{array}$ \\
\hline Hashimoto's thyroiditis & $\begin{array}{l}\text { Epilepsy with or without } \\
\text { occipital calcifications }\end{array}$ & $\begin{array}{l}\text { Turner } \\
\text { syndrome }\end{array}$ \\
\hline Graves' disease & Cerebellar ataxia & $\begin{array}{l}\text { William's } \\
\text { syndrome }\end{array}$ \\
\hline Autoimmune hepatitis & Peripheral neuropathy & \\
\hline $\begin{array}{l}\text { Primary biliary } \\
\text { cholangitis }\end{array}$ & Multiple myoclonic seizures & \\
\hline $\begin{array}{l}\text { Primary sclerosing } \\
\text { cholangitis }\end{array}$ & Multiple sclerosis & \\
\hline $\begin{array}{l}\text { Dermatitis } \\
\text { herpetiformis }\end{array}$ & Cerebral atrophy & \\
\hline Vitiligo & $\begin{array}{l}\text { Chronic inflammatory intestinal } \\
\text { diseases }\end{array}$ & \\
\hline Addison's disease & Sarcoidosis & \\
\hline Alopecia & Atopy & \\
\hline \multicolumn{3}{|l|}{ Psoriasis } \\
\hline \multicolumn{3}{|l|}{ IgA deficiency } \\
\hline \multicolumn{3}{|l|}{$\begin{array}{l}\text { Autoimmune atrophic } \\
\text { gastritis }\end{array}$} \\
\hline \multicolumn{3}{|l|}{$\begin{array}{l}\text { Autoimmune hemolytic } \\
\text { anemia }\end{array}$} \\
\hline \multicolumn{3}{|l|}{ Sjogren's syndrome } \\
\hline \multicolumn{3}{|l|}{ Scleroderma } \\
\hline \multicolumn{3}{|l|}{$\begin{array}{l}\text { Systemic erythematosus } \\
\text { lupus }\end{array}$} \\
\hline \multicolumn{3}{|l|}{ Polymyositis } \\
\hline \multicolumn{3}{|l|}{ Rheumatoid arthritis } \\
\hline \multicolumn{3}{|l|}{ Myasthenia gravis } \\
\hline $\begin{array}{l}\text { IgA nephropathy } \\
\text { (Berger's disease) }\end{array}$ & & \\
\hline
\end{tabular}

lack of demonstrable serological markers along with clinical signs of severe malabsorption and atrophy of the intestinal mucosa [94]. This form should be included in the differential diagnosis with other diseases that cause atrophy of the intestinal villi. The term non-responsive CD indicates GI symptoms that persist despite a GFD of more than 12 months [95]; however, it does not differentiate between active $\mathrm{CD}$ and associated conditions, which can be responsible for symptom persistence (Fig. 3) and alternative terminology is discussed below.

\section{Diagnosis}

The gold standard for $\mathrm{CD}$ diagnosis is represented by the combination of mucosal changes detected by duodenal biopsy and by positivity of serological tests (antitTG antibodies, anti-endomysium antibodies (EmA), and deamidated gliadin peptide (DGP) antibodies). Despite the progress made in serology, no antibody test currently available provides a sensitivity and specificity of $100 \%$ (Table 3) [96, 97], thus requiring intestinal biopsy as a key adjunct for establishing a correct diagnosis [98]. Pediatric patients with high titers (over 10 times the cutoff) of anti-tTG antibodies, detectable EmA, HLA-DQ2/ HLA-DQ8 positivity, and signs/symptoms suggestive of CD may skip duodenal biopsy as recommended by recent guidelines by the European Society for Paediatric Gastroenterology Hepatology and Nutrition (ESPGHAN) [99]. Although a large multicenter European study showed diagnostic accuracy of ESPGHAN criteria in identifying CD in children [100], it should be pointed out that these criteria are not followed worldwide. In fact, in some countries such as the USA, ESPGHAN criteria are not recommended because of the poor reproducibility of the anti-tTG assays [101]. Both advantages and disadvantages exist to biopsy for children with suspected celiac disease; however, most pediatric cases, especially those with low to medium anti-tTG2 titers, require histopathological assessment to confirm celiac disease diagnosis. In a recent study, Fuchs et al. [102] showed that the combination of anti-tTG (over 10 times the cut-off), EmA, and HLA-DQ2/HLA-DQ8 positivity (triple criteria) had a good accuracy across the range of pre-test probabilities in detecting adult patients with $\mathrm{CD}$. Nonetheless, duodenal biopsy still represents a pillar in the diagnosis of adult patients with suspected CD.

Current standard of care is based on the "four out of five rule" [103], which indicates that four out of five of the following criteria are enough to establish CD diagnosis: (1) typical signs and symptoms (diarrhea and malabsorption); (2) antibody positivity; (3) HLA-DQ2 and/or HLA-DQ8 positivity; (4) intestinal damage (i.e., villous atrophy and minor lesions); and (5) clinical response to GFD. Additionally, this rule helps physicians to identify the various subtypes of $C D$, i.e., seronegative $C D(a b-$ sence of point 2), potential CD (absence of point 4), non-classic $\mathrm{CD}$ (absence of point 1 ), and non-responsive $\mathrm{CD}$ (absence of point 5).

\section{Hematology and blood biochemistry tests}

Routine blood tests can lead to suspect CD [104]. Low serum levels of hemoglobin, albumin, calcium, potassium, magnesium, and phosphorus are more commonly detected in $\mathrm{CD}$ with a classic rather than non-classic phenotype. Most patients develop an iron deficiency microcytic anemia with low ferritin values. Normocytic, macrocytic, or dimorphic anemia is less common in CD patients with an increased variability in the size of red blood cells due to concomitant malabsorption of folate and/or vitamin B12, particularly in cases associated with autoimmune atrophic gastritis [73]. Elevated levels of bone-specific alkaline phosphatase and a significant vitamin D3 deficiency can be found in patients with $C D$ and 


\section{Continuous gluten exposure \\ OACD $\{$ Slow response to gluten withdrawal \\ Refractory celiac disease \\ Microscopic colitis \\ Irritable bowel syndrome \\ Small intestine bacterial overgrowth \\ ACDC $\{$ Lactose / fructose intolerance \\ Diverticular disease \\ Crohn's disease \\ Pancreatic insufficiency \\ Drug-induced enteropathy}

Fig. 3 Causes of ongoing signs and/or symptoms of celiac disease (CD) despite a gluten-free diet (formerly referred to as 'non-responsive' CD). In this review, two clinical phenotypes have been proposed - ongoing active celiac disease (OACD), related to three main causes, and associated celiac disease conditions (ACDC), encompassing a wide array of diseases

osteopenia/osteoporosis [105]. A cryptogenic increase of transaminases may herald the presentation of $\mathrm{CD}$ even in the absence of other relevant symptoms. Notably, transaminases revert to normal within 6-12 months of a GFD [76]. In a moderate percentage of adult CD patients, a blood smear can detect changes in the membrane and cytoplasm of red blood cells (i.e., Howell-Jolly bodies), whereas pitted red cells can be identified by Nomarski phase contrast microscopy; both these red blood cell abnormalities suggest an underlying hyposplenism [106]. Another sign of hyposplenism is the detection of a marked thrombocytosis in association with a small (in the most severe cases even undetectable) spleen revealed by ultrasound. Macroscopically evident or even functional (no major changes at imaging) hyposplenism is a predisposing factor for the development of infectious diseases due to encapsulated bacteria (e.g., Pneumococcus, Meningococcus), and is associated with autoimmune diseases and complications such as refractory CD, ulcerative jejunoileitis, and lymphoma [107, 108].

\section{Serology}

Over the last 20 years, the routine use of serological tests led to a significant increase in CD diagnoses. CD-related antibodies can identify subjects with suspected CD, further confirmed by histological evaluation [98]. In the early 1980s, anti-gliadin antibodies were the first serological marker used to screen patients at risk for CD. However, due to their low specificity, this serological test

Table 3 Performance of serological markers for a diagnosis of celiac disease

\begin{tabular}{llllll}
\hline & Sensitivity (\%) & Specificity (\%) & PPV (\%) & NPV (\%) & Diagnostic accuracy (\%) \\
\hline Anti-tTG IgA & 96.8 & 91.0 & 91.2 & 96.8 & 97.7 \\
EmA IgA & 93.7 & 100 & 100 & 94.4 & 96.9 \\
DGP IgG & 84.4 & 98.5 & 98.2 & 86.8 & 91.6 \\
\hline
\end{tabular}

Anti-tTG anti-transglutaminase antibodies, DGP direct antibodies against deamidated gliadin peptides, EmA anti-endomysium antibodies, NPV negative predictive value, PPV positive predictive value 
has been dismissed and its role is now confined to the possible identification of a subset of cases with nonceliac gluten/wheat sensitivity [109]. Currently, the serological diagnosis of $C D$ is based on tests that are highly predictive and widely validated, including EmA, antitTG, and DGP [97]. CD-related antibodies belong to IgA and IgG classes, but only those of IgA class can be regarded as highly sensitive and specific for CD [97]. The use of IgG markers (except for DGP) is often misleading due to the high percentage of false positives, and their use should be limited to patients with IgA deficiency [110]. EmA is the antibody test with the highest diagnostic accuracy since it offers an absolute specificity if tested in third-level laboratories by expert operators $[111,112]$. The sensitivity of anti-tTG IgA is higher than that of EmA IgA (97\% vs. 94\%), while the specificity of tTG IgA is certainly lower than that of EmA (91 and 99\%, respectively) (Table 3) [96]. False positives for antitTG normally display a low antibody titer (less than twice the cut off). A transient positivity for anti-tTG IgA, not associated with duodenal mucosal damage, has been reported in patients with type 1 diabetes at onset followed by a subsequent disappearance of antibodies within 6 months of their identification [113].

Another serological marker for CD is represented by DGP [96]. Compared to native peptides, the deamidation of gliadin by tTG makes the modified gliadin peptides more immunogenic. Initial studies reported an elevated sensitivity and specificity for CD [96], although other data showed a decrease in diagnostic accuracy [114]. IgG DGP are particularly useful in identifying CD in early childhood (age $<2$ years) [115]. IgA DGP have been shown to be of little usefulness in diagnosing $C D$ and therefore are not recommended for diagnosis [97]. In adult $\mathrm{CD}$, serology should include testing anti-tTG IgA along with total IgA. Should anti-tTG IgA be positive at a high titer with normal total IgA level, a duodenal biopsy can be performed without assessing EmA. With a low titer anti-tTG IgA, EmA IgA testing is necessary and, if positive, a duodenal biopsy should be recommended to confirm CD diagnosis (Fig. 4).

Strict compliance with a GFD in most CD patients leads to the disappearance or significant decrease of antibodies within 12 months $(18-24$ months if the antibody titer is very high) together with regrowth of the intestinal villi. IgA anti-tTG antibodies are the most commonly used test to monitor $\mathrm{CD}$ patients during follow-up, although their disappearance does not reflect the regrowth of intestinal villi $[97,116]$. Recent data from Choung et al. [117] demonstrated a very high specificity and sensibility of a new assay directed to identify the serum immune response to epitopes of the tTGDGP complex. In addition to diagnosis, such markers can be useful for follow-up purposes, although further studies are eagerly needed. While waiting for the validation of a tTG-DGP complex assay, current serology is not enough for evaluating the response to GFD and the regrowth of villi $[118,119]$.

\section{Duodenal biopsy}

Morphological evaluation of the duodenal biopsy is still of critical importance for confirming CD diagnosis. Histology remains the 'gold standard' for CD diagnosis [94]. In recent years, however, the histological criteria for $C D$ have radically changed with the inclusion of mild villous atrophy and minimal lesions (characterized by an isolated increase in IELs) as possible expression of glutenrelated intestinal damage $[120,121]$. Current recommendations are for four biopsies on the second duodenal portion and two biopsies at the bulb [122]. A fundamental principle for the correct evaluation is the orientation of biopsy samples using cellulose acetate Millipore filters $[123,124]$. The different types of CD-related lesions of the intestinal mucosa can be categorized into five stages according to the Marsh classification, modified by Oberhüber, which is currently used in all reference centers for the diagnosis of CD [120]. Type 1 and type 2 lesions, characterized by an increase in IELs (with or without crypt hyperplasia) and normal villi, compatible with, but non-specific for $\mathrm{CD}$. Together with positive anti-tTG and $\mathrm{EmA}$, minimal intestinal lesions indicate potential CD. In most cases, minimal lesions are attributable to other causes, including food allergies (e.g., cow milk proteins), Crohn's disease, lymphocytic colitis, bacterial and parasitic intestinal infections, such as Giardia, common variable immunodeficiency, small intestinal bacterial overgrowth, non-steroidal anti-inflammatory drugs, and Helicobacter pylori infection (Box 1) [125-127].

In recent years, there has been a worrying increase in the number of diagnoses of $\mathrm{CD}$ incorrectly based on minimal lesions with no genetic and serological markers [128]. The IEL cytometric pattern is more accurate than subepithelial deposits of anti-TG2 IgA for identifying CD in lymphocytic enteritis [129]. The normal IEL cutoff has been established to be $\geq 25$ lymphocytes over 100 epithelial cells. Even if it is well established that coeliac patients always display IEL counts $\geq 25 \%$, a recent paper stressed the importance of a high IEL count for CD diagnosis underlining that the mean IEL count in untreated CD was $54 \pm 18 / 100$ enterocytes, whereas in non-CD patients the value was $13 \pm 8$ [130]. The typical lesion of $C D$ shows villous atrophy with a change in the villi-to-crypt ratio (<3:1 to $1: 1)$ and an increase in IEL. This lesion, defined as type 3 in the Marsh-Oberhüber classification, is in turn subdivided into three stages depending on the severity of the atrophy, namely mild (3a), partial (3b), and subtotal atrophy (3c) [120]. Recently, Marsh et al. [131, 132] argued against Oberhüber's lesion 


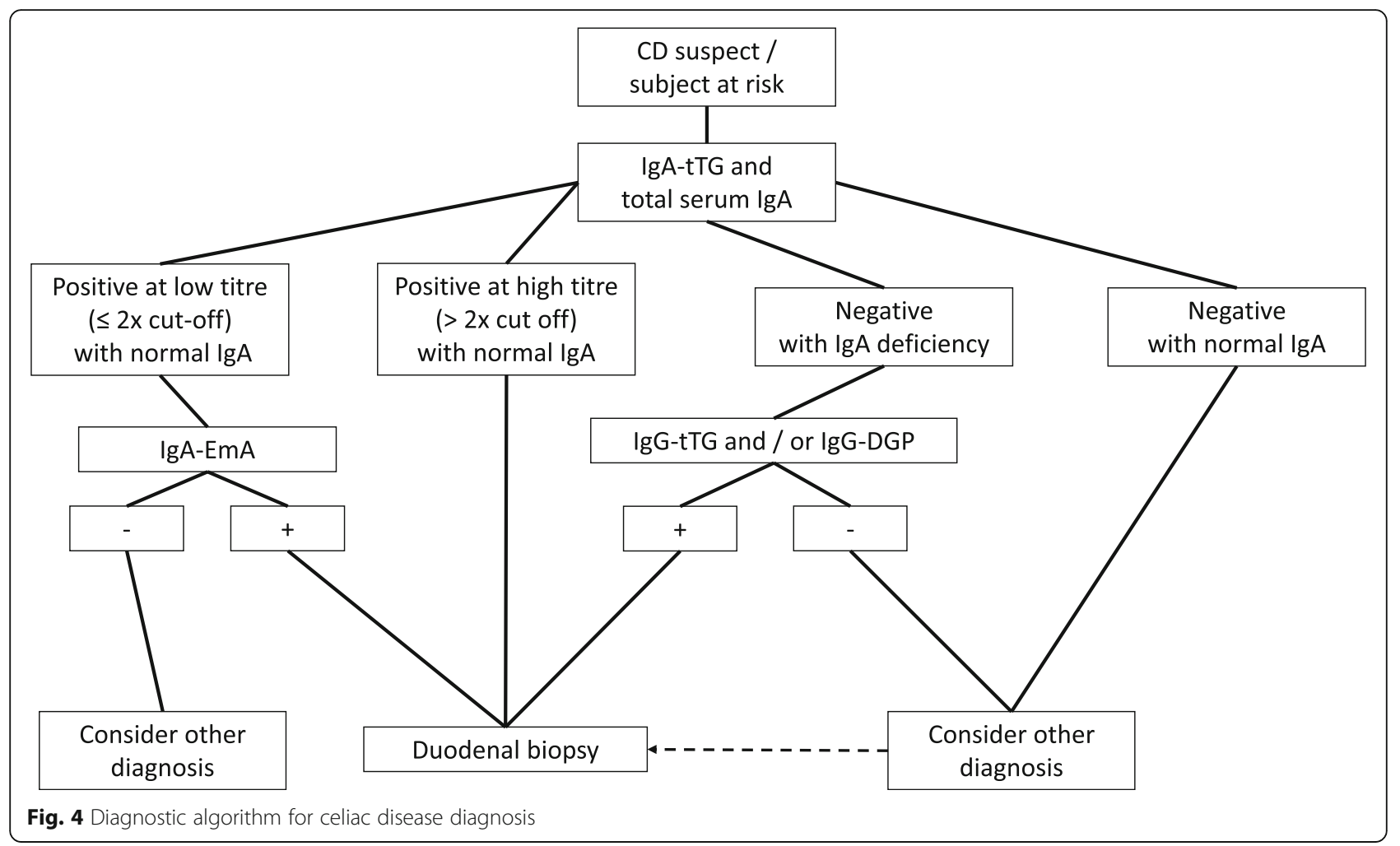

III sub-division, claiming that splitting intestinal atrophy in three stages can be clinically irrelevant and sometimes misleading. In line with this theory no significant difference in IEL count was observed in mild, partial, and subtotal villous atrophy [130]. In an attempt to simplify the histopathological grading and therefore the relationship between pathologists and clinicians, Corazza and Villanacci proposed a classification from five to three stages [121]. Notably, the lesions that characterize CD were divided into two categories - non-atrophic (grade A) and atrophic (grade B) - with the latter being further subcategorized into $\mathrm{B} 1$, in which the villi-to-crypt ratio is less than 3:1 (with identifiable villi), and B2, in which villi are entirely atrophic. Grade A lesions, characterized by a pathological increase in the number of IELs, better identified by immunohistochemical staining for CD3, include type 1 and 2 lesions based on the Marsh-Oberhüber classification; grade $\mathrm{B} 1$ lesions include the $3 \mathrm{a}$ and $3 \mathrm{~b}$ lesions, while grade B2 corresponds to 3c (Fig. 5) [121]. In some patients with more distal disease or in those with contraindication to biopsy, videocapsule endoscopy can be recommended [133].

\section{Classification of variants of $C D$ Potential CD}

In recent years, an increasing number of patients have antibody positivity (IgA EmA and anti-tTG) for CD with HLA-DQ2/HLA-DQ8 and lack of villous atrophy [134,
135]. For this category of patients, which represents around $10 \%$ of subjects with $\mathrm{CD}$, the term potential celiac disease has been adopted [69]. In patients with potential CD the intestinal mucosa may be normal (Marsh 0 ) or slightly inflamed (increased number of IELs, i.e., Marsh 1) [135]. Despite the absence of severe lesions in the intestinal mucosa, these patients may have GI and/ or extraintestinal symptoms or be entirely asymptomatic $[2,135]$. Although the criteria for diagnosing this condition are clear, potential CD still remains a poorly studied area, with many unsettled questions and contrasting results in the studies conducted so far [135-141]. In children, over $80 \%$ of patients with potential CD are asymptomatic and the remaining $20 \%$ more commonly experience intestinal symptoms such as malabsorption, chronic diarrhea, and recurrent abdominal pain rather than extraintestinal signs such as iron-deficiency anemia, hypertransaminasemia, and short stature [137, 138, 141]. In adults, however, several studies have shown that the symptomatic phenotype in subjects with potential CD is much more common than in children, and it is primarily characterized by extraintestinal symptoms $[135,136$, $139,140]$. One controversial issue concerns whether subjects with potential CD should be treated by a GFD. The actual evidence suggests that a GFD should be recommended only to subjects with symptomatic potential $\mathrm{CD}$. On the other hand, patients with asymptomatic potential $\mathrm{CD}$ are allowed to continue a gluten-containing 


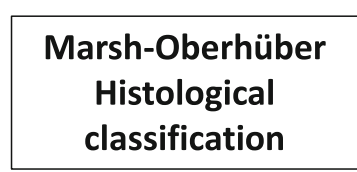

Corazza Villanacci

Histological

classification
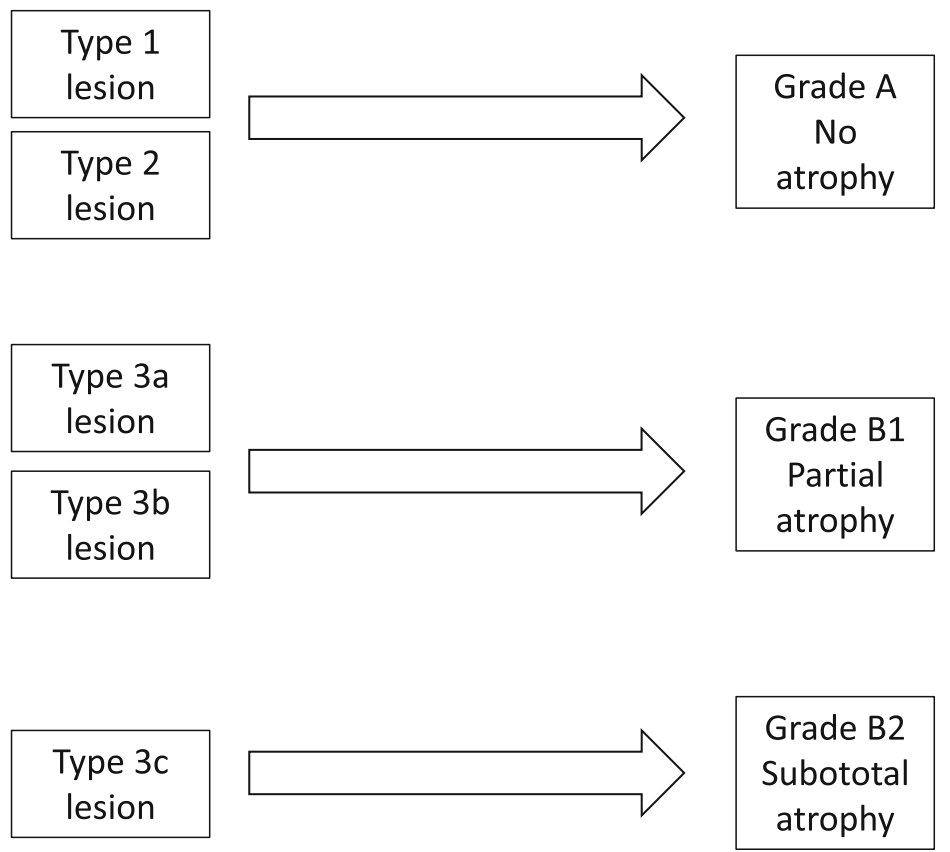

Fig. 5 Comparison between the two classifications for the duodenal biopsy

diet while being followed-up with close clinical, serological, and histological control visits (in our experience every 6 months) [135-140]. Studies have reported possible fluctuation with spontaneous normalization of serological markers in patients with potential CD left on a gluten-containing diet. Few patients with potential CD consuming a gluten-containing diet develop full-blown villous atrophy $[135,137,138,140,142]$. In our study, only $6 \%$ of these subjects developed villous atrophy over a mean follow-up period of 3 years, whereas symptomatic subjects should be treated as they show a clear clinical improvement in symptoms with a GFD [135].

\section{Seronegative CD}

Although the specific antibodies for $\mathrm{CD}$ can be detected in the vast majority of patients, a small number of $\mathrm{CD}$ patients (around 2-3\%) test negative for serological markers. In these cases, the diagnosis is closely connected to the detection of villous atrophy on the duodenal histology [94, 139, 143]. Performing a genetic test for $C D$ remains a fundamental step since its negative result definitively rules out the disease and prompts physicians to seek for other causes of villous atrophy. A seronegative $\mathrm{CD}$ can be confirmed 1 year after the beginning of a GFD, a convenient time to demonstrate an improvement in both symptoms and histology. The diagnostic complexity of this particular variant of $C D$ is due to the differential diagnosis with other conditions involving villous atrophy, such as parasitic infections (Giardia lamblia), autoimmune enteropathy, bacterial contamination of the small intestine, common variable immunodeficiency, eosinophilic gastroenteritis, druginduced enteropathy (angiotensin II receptor antagonists, i.e., olmesartan and other sartans, non-steroidal anti-inflammatory drugs, and mycophenolate), intestinal lymphoma, Crohn's disease, tropical sprue, HIV enteropathy, and Whipple disease (Fig. 6) [94, 144, 145]. Of all villous atrophies lacking $C D$ antibodies, $28-45 \%$ are due to an underlying seronegative CD [94, 146, 147]. Seronegative $C D$ patients display a classic clinical phenotype, characterized by diarrhea and malabsorption, a clear female gender prevalence, and have a higher risk of morbidity and mortality compared with antibody-positive CD patients [94, 147]. Furthermore, compared to classic CD, seronegative patients have a greater association with autoimmune diseases and a higher risk of developing refractory disease. This increased morbidity could be partly due to the late diagnosis of this condition, which on average is around 50 years of age [94]. 


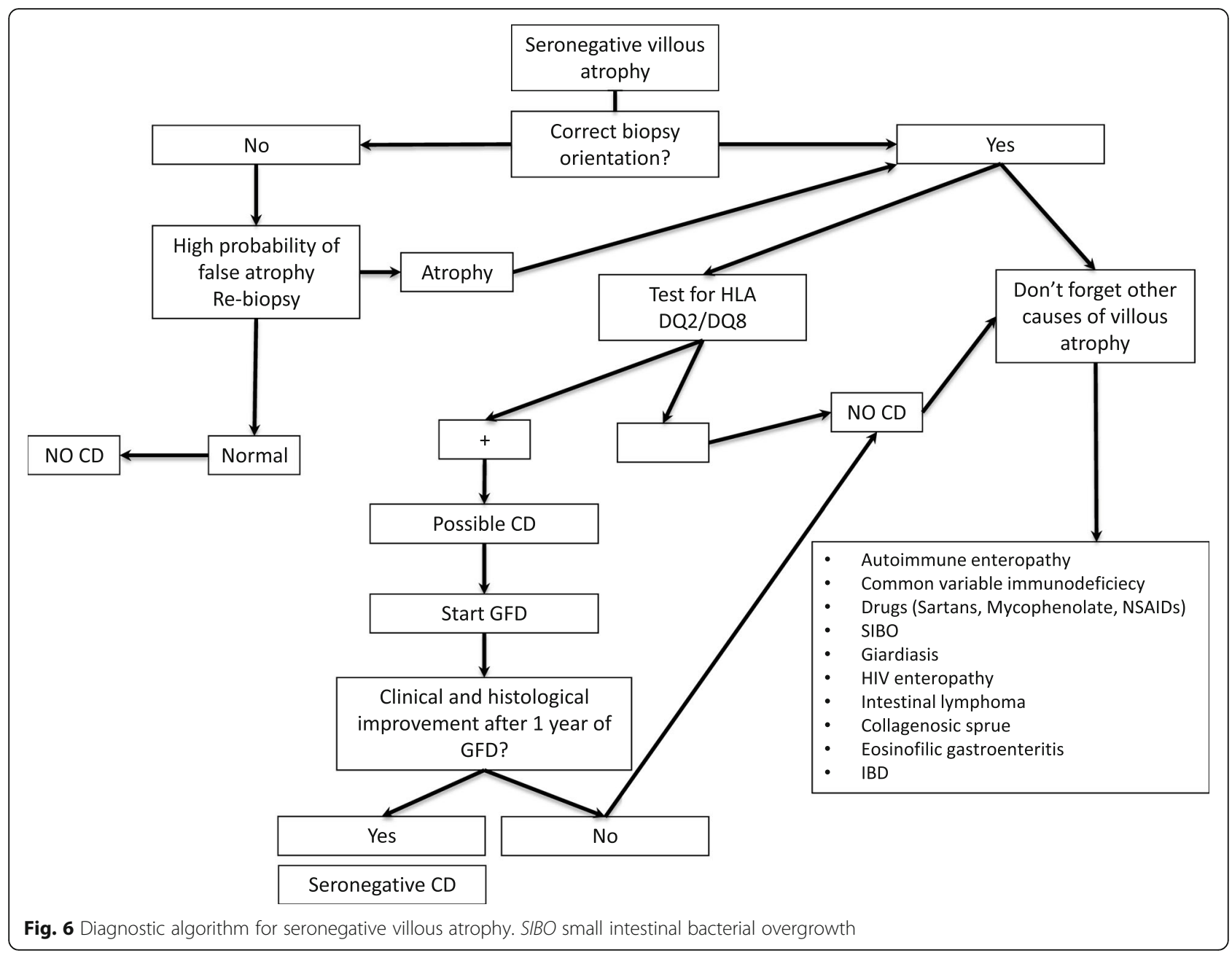

\section{Assessment of ongoing signs and symptoms in CD}

The majority of the patients with $\mathrm{CD}$ exhibit a symptomatic and mucosal response to the GFD. Some patients, however, fail to have complete control of symptoms and normalization of villous structure despite attempted adherence to the GFD. These patients have traditionally been referred to as non-responsive CD [95, 148]; however, this terminology has resulted in confusion as, in many cases, manifestations are due to associated conditions rather than $\mathrm{CD}$. In light of both emerging tests for $\mathrm{CD}$ monitoring, such as GIPs, and emerging novel therapies for active CD, we propose updating this classification (formerly nonresponsive $\mathrm{CD}$ ). When evaluating a patient with $\mathrm{CD}$ on a GFD and with ongoing signs or symptoms, the initial step is the differentiation between ongoing active $\mathrm{CD}$ (OACD) and the presence of associated $\mathrm{CD}$ conditions (ACDCs). OACD can be seen in three scenarios - (1) slow response, where there is progressive improvement in symptoms and mucosal damage, but full remission does not occur for at least 1-2 years; (2) RCD, where there is ongoing severe enteropathy and malabsorptive symptoms after 6-12 months on a GFD; and (3) gluten exposure, where, despite adequate understanding of the GFD and attempted adherence, gluten avoidance is insufficient to result in symptomatic or histologic remission. This is the most frequent cause of OACD and can be due to very high sensitivity to a low level of gluten exposure or an inability of the patient to achieve standard recommended gluten restriction. Conversely, when patients with ongoing symptoms are found not to have $\mathrm{OACD}$, generally when small bowel assessment shows minimal ongoing enteropathy and significant gluten exposure is excluded, investigation of possible ACDCs is recommended. ACDCs include IBS, small intestinal bacterial overgrowth, microscopic colitis, lactose intolerance, fructose intolerance, diverticular disease, Crohn's disease, pancreatic insufficiency, and autoimmune and drug-induced enteropathy, and should be evaluated according to clinical suspicion (Fig. 3) [95, 148].

\section{CD complications}

It has been widely shown that a late diagnosis of $\mathrm{CD}$ (after the age of 50) and/or not following a strict GFD can lead to a higher mortality compared to that of the 
general population [149]. Although rare (around 1\% of patients diagnosed with $\mathrm{CD}$ ) [150], the complications of $\mathrm{CD}$ include hyposplenism, RCD, intestinal lymphoma, small bowel adenocarcinoma, and ulcerative jejunoileitis. Complications should be suspected in all patients who, despite adherence to a GFD, complain of an unexplained persistence or re-exacerbation of symptoms (i.e., diarrhea, intestinal sub-occlusion, abdominal pain, weight loss, fever, and severe asthenia). These complications occur more commonly when a diagnosis of $\mathrm{CD}$ was established in elderly patients and/or in those who are homozygous for DQ2 not observing a strict GFD [151].

\section{Hyposplenism}

Anatomical or functional hyposplenism can be identified in around $30 \%$ of adult patients with $\mathrm{CD}$, with prevalence increasing up to $80 \%$ in patients with complications $[107,152]$. In $\mathrm{CD}$ cases, the detection of a small-size spleen on abdominal ultrasound should guide physicians to confirm functional hyposplenism by evaluating Howell-Jolly bodies (on a peripheral blood smear) or pitted red cells with phasecontrast microscopy (see above) [107, 152]. Splenic hypofunction is closely associated not only with the development of complications and other autoimmune diseases associated with $\mathrm{CD}$ but also encapsulated bacterial infections (i.e., Pneumococcus, Haemophilus influenzae, Meningococcus) [107]. Because of the greater risk of developing infections (in some cases lethal or with severe sequelae) from encapsulated bacteria, anti-pneumococcal and anti-meningococcal vaccinations are recommended in this subgroup of patients $[106,107,152]$.

\section{Refractory CD}

RCD represents about $10 \%$ of all OACD cases [148] and approximately $1-1.5 \%$ of total cases of CD [153]. This condition is characterized by symptoms of malabsorption, weight loss, and diarrhea associated with persistent villous atrophy after at least 1 year on a strict GFD, confirmed by negative CD serology [69]. Before thinking of RCD, physicians should rule out other more frequent causes of ongoing signs and symptoms of CD, as previously reported $[95,148]$. Refractory CD is in turn subdivided into two categories, primary and secondary, depending on whether the patients had a symptomatic response since the beginning of GFD, or they had a recurrence of symptoms after a more or less long period of improvement.

There are two subtypes of RCD - type 1 , where the IEL population has a normal $\mathrm{CD} 3^{+} \mathrm{CD} 8^{+}$phenotype, and type 2 , with a clonal presentation of surface $\mathrm{CD}^{-}$/intracytoplasmic $\mathrm{CD}^{+}$IELs along with monoclonal rearrangement of the gamma-chain of the $\mathrm{T}$ cell receptor [153]. This distinction into two subtypes is fundamental for therapeutic management and prognosis; in fact, type
2 displays a 5 -year mortality rate of $55 \%$ vs. $7 \%$ for type 1 [154]. The mortality of patients with type $2 \mathrm{RCD}$ is primarily due to the development of intestinal lymphoma, which appears to occur more often in male patients, although $\mathrm{CD}$ is more commonly detectable in female patients (female-to-male ratio 3:1) [155]. A diagnosis of RCD should always be suspected by persistent villous atrophy despite a strict, 1-year GFD, negative serology (some cases may show the persistence of low-titer CD-related antibodies), the exclusion of other causes of persistent villous atrophy, and phenotyping of the intestinal lymphocytic population aimed to confirm the presence (type 2) or absence (type 1) of a monoclonal rearrangement of $\mathrm{T}$ cell receptor. In all cases of type 2 $\mathrm{RCD}$, it is essential to perform, at diagnosis, a computed tomography (CT) and/or magnetic resonance (MR) enterography followed by positron emission tomography (PET), capsule endoscopy, and enteroscopy in order to rule out the progression to intestinal lymphoma [152, 154]. Due to this risk, in subjects with a diagnosis of type 2 RCD, a capsule endoscopy has been recommended once a year at the follow-up [156]. From a therapeutic perspective, the management of type $1 \mathrm{RCD}$ is based on immunosuppressive therapy containing steroids, azathioprine, 6-mercaptopurine, and methotrexate, whereas type 2 therapy is based on additional medications, including cyclosporine and chemotherapy such as cladribine and fludarabine associated with antiCD52 monoclonal antibodies (alemtuzumab). Promising results have been recently reported by treating patients with anti-IL-15 antibodies (AMG-714). In certain cases, an autologous stem cell transplantation has been attempted with promising results [154-156].

\section{Intestinal lymphoma}

The association between $\mathrm{CD}$ and cancers has been known for over 50 years [157] and a delayed diagnosis of $\mathrm{CD}$ exposes patients to an increased risk of developing neoplastic diseases [158]. In recent years, several studies have reported a growing incidence from 6 to 9 times higher than that of the general population for nonHodgkin $T$ cell intestinal lymphoma and, to a lesser extent, also B cell lymphoma [158]. In most cases, the development of intestinal lymphoma is preceded by type 2 RCD that develops into malignant disease in $33-52 \%$ of cases within 5 years from diagnosis. More rarely, intestinal lymphoma may develop from type $1 \mathrm{RCD}$, with a rate of $14 \%$ over 5 years [159]. Treatment in cases of CD-related intestinal lymphoma involves chemotherapy, i.e., high-dose ifosfamide, epirubicin, and etoposide methotrexate, followed by autologous stem cell transplantation. If lymphoma includes an elevated expression of CD30 (> 80\% of the neoplasm) it is possible to use biologic therapy with anti-CD30 associated with 
monomethyl auristatin E (brentuximab vedotin) and a chemotherapy regimen containing cyclophosphamidedoxorubicin-prednisone followed by autologous stem cell transplantation [159]. Recent data indicate that NKp46, a NK receptor expressed by lymphocytes, can be a biomarker as well as a possible therapeutic target for $\mathrm{T}$ cell lymphoproliferative diseases, i.e., type $2 \mathrm{RCD}$ and enteropathy-associated $\mathrm{T}$ cell lymphoma [160].

\section{Small bowel adenocarcinoma}

Small bowel adenocarcinoma is an extremely rare cancer in the general population ( 5.7 cases/1,000,000 people per year) but it is much more common in patients with $C D$ (odds ratio reported in the literature ranges between 4.3 to 60.0), usually being detectable in the jejunum [161]. Compared to lymphomas, small bowel adenocarcinoma is rare, although increasingly detectable in the clinic. Nowadays, however, the diagnosis of this cancer occurs together with $\mathrm{CD}$. Unlike intestinal lymphoma, the small bowel adenocarcinoma is not preceded by RCD and occurs more commonly in female patients [150]. The onset of a sudden intestinal (sub)/occlusion and/or anemia, particularly in patients with a late diagnosis of $\mathrm{CD}$ and patients who have been following a GFD for a short period of time, are clinical features suggestive of an underlying small bowel adenocarcinoma. A thorough diagnostic work-up is mandatory and requires a wide array of imaging tests (e.g., CT/MR-enterography, PET, capsule endoscopy, and enteroscopy) [162].

\section{Follow-up for CD in adults}

A well-defined follow-up strategy should be agreed by physicians and patients once $\mathrm{CD}$ has been diagnosed. Usually, the first follow-up visit is planned within 6 months from diagnosis and then every 12-24 months (every 3-6 months if complications occur) is adequate to confirm compliance with the GFD, rule out the onset of autoimmune diseases and metabolic changes, and, most importantly, to allow for the early diagnosis of any complications [163]. Patients should undergo a consultation with a dietician and follow-up blood tests including complete blood count, anti-tTG IgA (or IgG in case of IgA deficiency), thyroid stimulating hormone, antithyroidperoxidase, anti-thyroglobulin, ferritin, folate, vitamin D3, transaminases, and a metabolic profile [163]. The first follow-up should include a screening of antinuclear antibodies and non-organ-specific autoantibodies in order to rule out the presence of markers predictive of autoimmune diseases associated with $\mathrm{CD}$. Should the antinuclear antibodies test reveal a high titer along with extractable nuclear antigen antibody positivity, this information might be useful to investigate for other autoimmune $\mathrm{CD}$-associated disorders, e.g., primary biliary cholangitis and Sjogren syndrome [2]. In adults, a bone density scan should be performed after 12-18 months of a GFD and repeated regularly only if abnormal or in case of other indications. Subjects with osteopenia should be treated with supplements containing calcium and vitamin $\mathrm{D}$, while possible treatment with bisphosphonates should be considered in cases of osteoporosis. Body weight increase may occur as a consequence of an excessive consumption of dietary products high in vegetable fats (colza, palm, and coconut oil) commonly present in GFD [164]. Therefore, nutritional counselling is advisable to prevent metabolic complications, including liver steatosis, during follow-up. On the other hand, patients who are starting GFD should be tested with an abdominal ultrasound to exclude spleen abnormality (i.e., hyposplenism) [165].

Notwithstanding a strict GFD, CD patients may experience abdominal symptoms ascribable to IBS in 30 $50 \%$ of cases; these symptoms may respond to dietary recommendations (e.g., reduction of insoluble fiber intake or fermentable oligosaccharides, disaccharides, monosaccharides, and polyols) as well as symptomatic drug therapy [166].

A self-adapted GFD, without the support of a nutritionist, can cause vitamin and trace metal deficiency, which should be supplemented if needed, particularly when patients report the onset of asthenia [167]. Additionally, constipation, which can be associated with a GFD, requires appropriate management based on nonirritant (e.g., osmotic) laxatives [168].

Should a CD-related complication occur, follow-up visits should be more frequent, i.e., every 3-6 months [156]. In these circumstances, in addition to standard tests (as previously listed), protein electrophoresis, lactate dehydrogenase, and beta- 2 microglobulin testing should be included. Upper endoscopy should be performed (with new duodenal biopsies) along with abdominal ultrasound, as well as CT/MR-enterography, PET, capsule endoscopy, and enteroscopy [154-156].

Physicians may consider (even if not recommended by current guidelines) performing a follow-up duodenal biopsy in adults in order to check the regrowth of villi in patients on a GFD, keeping in mind that the average time to the restitutio ad integrum of the villi could take up to 3 years. A second duodenal biopsy after GFD should be recommended only in those patients with persisting symptoms and demonstrable laboratory deficiencies of micronutrients [133].

Finally, GIP assessment, a controversial test still awaiting further validation, can be performed on stool samples and may be useful for monitoring the adherence to a GFD [48].

\section{Follow-up for CD in children}

Currently, the follow-up of $\mathrm{CD}$ in children is lacking standardized evidence-based recommendations [169]. 
Children with CD should be followed up after 6 months from diagnosis and then every year in order to check symptomatic improvement, adherence to GFD, quality of life, and progressive normalization of CD-related antibodies. Laboratory tests and biochemical evaluation is crucial in these patients and should be tailored on caseby-case basis. As for adults, autoimmune thyroiditis should always be screened. Duodenal biopsy monitoring is unnecessary after a GFD has been instituted. However, should the patient have no or partial clinical response to gluten withdrawal, a careful assessment should be recommended to rule out inadvertent gluten ingestion or poor adherence to a GFD. Furthermore, in this subset of poorly responsive patients, a duodenal histopathology is advisable [119, 169]. At variance to adults, children hardly ever develop complications, indeed only a few case reports of refractory CD have been reported [170].

\section{Diet and new treatments}

Currently, the only effective treatment available for $C D$ is a strict GFD for life since it leads to the resolution of intestinal and extraintestinal symptoms, negativity of autoantibodies, and the regrowth of the intestinal villi. In addition, the diet offers a partial protective effect towards several complications. However, these crucial advantages are accompanied by some disadvantages, including a negative impact on quality of life, psychological problems, fear of involuntary/inadvertent contamination with gluten (as demonstrated in multicenter GIP studies) [48], possible vitamin and mineral deficiencies, metabolic syndrome, an increased cardiovascular risk, and often severe constipation [171-173]. Most of these CD-related drawbacks can be overcome by instructing the patient about the risks of an uncontrolled gluten-free regimen and by providing nutritional recommendations by a dietician with experience in CD. From a psychological perspective, the support a psychologist could be highly useful in accepting the disease [174].

Due to the relevant burden induced by gluten withdrawal with consequent worsening of quality of life, about $40 \%$ of $C D$ patients are unsatisfied with their alimentary regimen and they would be keen to explore alternative treatments [175]. In recent years, researchers have attempted to meet the requests of $C D$ patients seeking therapies different from diet [176]. Clinical trials are currently in progress, but only few have reached later clinical trial phases, namely those with larazotide acetate and gluten-specific proteases from a bacterial mix (ALV003) [177-180]. Larazotide acetate is a zonulin antagonist blocking tight junction disassembly, thereby limiting gluten crossing a permeable intestinal mucosal barrier [177]. Larazotide has shown efficacy in glutenrelated symptom control rather than in restoring complete epithelial barrier integrity and preventing gluten from crossing the mucosal lining [177]. Taken together, the data so far published indicate that larazotide may be beneficial in allowing patients to tolerate minimal amounts of gluten such as those derived from inadvertent ingestion or probably for 'gluten-free holidays', i.e., a short period during which patients are allowed to eat a minimal amount of gluten. ALV003 targets gluten and degrades it into small fragments in the stomach before they pass into the duodenum [178]. This strategy has also been demonstrated to be able to 'digest' only small quantities of gluten and thus would be effective against contamination but not to protect patients from the effects driven by large quantities of gluten [178]. However, a recent phase $2 b$ study by Murray et al. [180] showed that ALV003 (or latiglutenase) did not improve histologic and symptoms scores in 494 CD patients with moderate to severe symptoms versus placebo. IL-15 monoclonal antibodies (AMG 714) are being investigated in phase 2 studies in both gluten challenge and RCD type II patients, but additional safety studies are needed for the acquisition and competition of the license. Finally, vaccination (Nexvax2) is another possible therapeutic strategy aimed at desensitizing patients with $\mathrm{CD}$ to gliadin peptides. Although abdominal pain and vomiting were major side effects, the trial passed phase 1 . Vaccines could represent a definitive cure for CD should data show actual efficacy [181].

\section{Can $\mathrm{CD}$ be prevented?}

Several retrospective studies have suggested that breastfeeding, modality of delivery, and time of gluten introduction in the diet of infants at risk for $\mathrm{CD}$ may affect the incidence of the disease. However, the data supporting the role of these factors in the risk of developing $\mathrm{CD}$ is limited by their retrospective design and have been criticized by alternative interpretations [182-184]. Two recent landmark studies $[19,21]$, which prospectively screened infants with a first-degree family member with $C D$ from birth, found that $\mathrm{CD}$ develops quite early in life in this risk group, demonstrating that early environmental factors may be crucial in the development of $\mathrm{CD}$. However, these studies failed to identify possible targets to prevent $\mathrm{CD}$, leading to the gut microbiota as the key element to scrutinize for possible innovative preventive strategies. In this line, viral (e.g., rotavirus) GI infections may potentiate subsequent development of $\mathrm{CD}$. Thus, rotavirus vaccination seems to significantly decrease the risk of $\mathrm{CD}$, in particular among children with early (before 6 months of age) gluten exposure [185]. The ongoing Celiac Disease Genomic, Environment, Microbiome, and Metabolomic study has been designed to identify potential primary prevention targets by establishing microbiome, metabolomic, and/or environmental factors responsible for loss of gluten tolerance, thus switching genetic predisposition to clinical outcome [186]. 


\section{Conclusions}

Although there has been a substantial increase in the number of $\mathrm{CD}$ diagnoses over the last 30 years, many patients remain undiagnosed [187]. The flow-chart for identifying $\mathrm{CD}$ in adults must always include both serology and intestinal biopsy, whereas genetics should be performed only in selected cases. Diagnostic criteria should help physicians in avoiding misdiagnosis and missing cases of CD (i.e., seronegative patients with classic symptoms not undergoing biopsy) and preserve people from an unjustified GFD. The treatment for CD is still primarily a GFD, which requires significant patient education, motivation, and follow-up. Slow response occurs frequently, particularly in people diagnosed in adulthood. Persistent or recurring symptoms should lead to a review of the patient's original diagnosis, exclude alternative diagnoses, evaluation of GFD quality, and serologic testing as well as histological assessment in order to monitor disease activity. In addition, evaluation for disorders that could cause persistent symptoms and complications of $\mathrm{CD}$, such as refractory $C D$ or lymphoma, should be pursued. The future opens to new therapeutic and preventive strategies, which are expected to improve the patient's quality of life and pave the way to a definitive cure for this old disease.

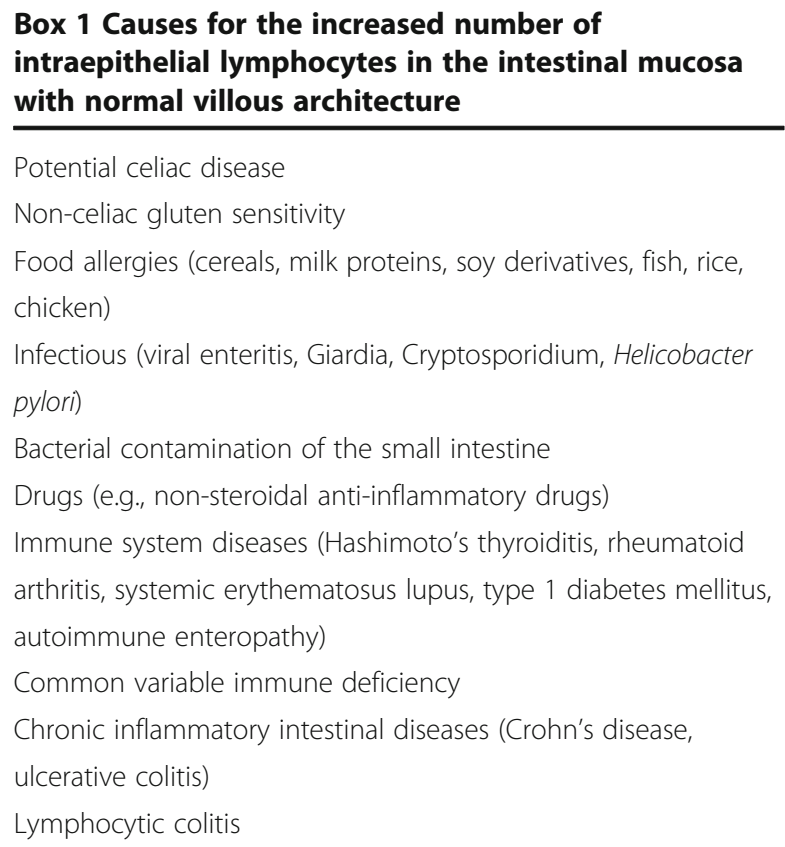

\section{Abbreviations}

ACDCs: Associated celiac disease conditions; CD: Celiac disease; CT: Computed tomography; DGP: Deamidated gliadin peptides antibodies: EmA: Anti-endomysial antibodies; ESPGHAN: European Society for Paediatric
Gastroenterology Hepatology and Nutrition; GFD: Gluten-free diet; Gl: Gastrointestinal; GIP: Gluten immunogenic peptides; HLA: Human leukocyte antigen; IBS: Irritable bowel syndrome; IELs: Intraepithelial lymphocytes; IL: Interleukin; MR: Magnetic resonance; NK: Natural killer; OACD: Ongoing active celiac disease; PET: Positron emission tomography; RCD: Refractory celiac disease; TG2: Transglutaminase 2; tTG: tissue transglutaminase

\section{Authors' contributions}

Wrote the first draft of the manuscript: GC. Writing, correction and addition of fundamental insights to the manuscript: GC, UV, AS, DL, RDeG, CC, AF. All authors read and approved the final manuscript.

\section{Funding}

This work was partially supported by the Fondo Incentivazione Ricerca (FIR) to R DeG, Fondi Ateneo per la Ricerca (FAR) to GC and RDe G (from University of Ferrara) and by the National Institute of Health grant R01DK104344 to AF.

\section{Availability of data and materials}

None.

Ethics approval and consent to participate

Not applicable.

\section{Consent for publication}

Not applicable.

\section{Competing interests}

The authors declare that they have no competing interests.

\section{Author details}

${ }^{1}$ Department of Medical Sciences, University of Ferrara, Via Aldo Moro 8, Cona, 44124 Ferrara, Italy. ${ }^{2}$ Center for Celiac Research and Treatment, Massachusetts General Hospital, Boston, MA 02114, USA. 'Department of Medical and Surgical Sciences, University of Bologna, 40138 Bologna, Italy.

${ }^{4}$ Takeda Pharmaceuticals International Co, Cambridge, MA 02139, USA.

${ }^{5}$ Division of Gastroenterology, Beth Israel Deaconess Medical Center, Boston, MA 02115, USA. 'Department of Pediatrics, Center for Celiac Research, Università Politecnica delle Marche, 60121 Ancona, Italy.

Received: 19 March 2019 Accepted: 27 June 2019

Published online: 23 July 2019

References

1. Fasano A, Catassi C. Celiac disease. N Engl J Med. 2012;367:2419-26.

2. Volta U, Caio G, Stanghellini V, De Giorgio R. The changing clinical profile of celiac disease: a 15-year experience (1998-2012) in an Italian referral center. BMC Gastroenterol. 2014;14:194.

3. Volta U, Caio G, Tovoli F, De Giorgio R. Non-celiac gluten sensitivity: questions still to be answered despite increasing awareness. Cell Mol Immunol. 2013:10:383-92.

4. de Lorgeril M, Salen P. Gluten and wheat intolerance today: are modern wheat strains involved? Int J Food Sci Nutr. 2014:65:577-81.

5. van den Broeck HC, de Jong HC, Salentijn EM, et al. Presence of celiac disease epitopes in modern and old hexaploid wheat varieties: wheat breeding may have contributed to increased prevalence of celiac disease. Theor Appl Genet. 2010:121:1527-39.

6. Bach JF. The hygiene hypothesis in autoimmunity: the role of pathogens and commensals. Nat Rev Immunol. 2018;18:105-20.

7. Corazza GR, Andreani ML, Biagi F, et al. The smaller size of the 'coeliac iceberg' in adults. Scand J Gastroenterol. 1997;32:917-9.

8. Ivarsson A, Persson LA, Juto $P$, et al. High prevalence of undiagnosed coeliac disease in adults: a Swedish population-based study. J Intern Med 1999:245:63-8.

9. Riestra S, Fernandez E, Rodrigo L, et al. Prevalence of coeliac disease in the general population of northern Spain. Scand J Gastroenterol. 2000; 35:398-402.

10. Volta U, Bellentani S, Bianchi FB, et al. High prevalence of celiac disease in Italian general population. Dig Dis Sci. 2001:46:1500-5. 
11. Mustalahti K, Catassi C, Reunanen A, et al. The prevalence of celiac disease in Europe: results of a centralized, international mass screening project. Ann Med. 2010;42:587-95.

12. Rubio-Tapia A, Ludvigsson JF, Brantner TL, et al. The prevalence of celiac disease in the United States. Am J Gastroenterol. 2012;107:1538-44.

13. Singh $P$, Arora $S$, Singh A, et al. Prevalence of celiac disease in Asia: a systematic review and meta-analysis. J Gastroenterol Hepatol. 2016;3: 1095-101.

14. Catassi C, Kryszak D, Bhatti B, et al. Natural history of celiac disease autoimmunity in a USA cohort followed since 1974. Ann Med. 2010;42:530-8.

15. Hall EJ, Batt RM. Dietary modulation of gluten sensitivity in a naturally occurring enteropathy of Irish setter dogs. Gut. 1992;33:198-205.

16. Okada H, Kuhn C, Feillet H, Bach J. The 'hygiene hypothesis' for autoimmune and allergic diseases: an update. Clin Exp Immunol. 2010;160: $1-9$.

17. Verdu EF, Galipeau HJ, Jabri B. Novel players in celiac disease pathogenesis: the role of gut microbiota. Nat Rev Gastroenterol Hepatol. 2015;185:2969-82.

18. Lundin KE, Wijmenga C. Coeliac disease and autoimmune disease-genetic overlap and screening. Nat Rev Gastroenterol Hepatol. 2015;12:507-15.

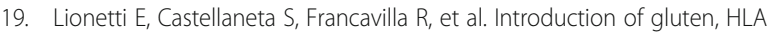
status, and the risk of celiac disease in children. N Engl J Med. 2014;371: 1295-303.

20. Liu E, Lee HS, Aronsson CA, et al. Risk of pediatric celiac disease according to HLA haplotype and country. N Engl J Med. 2014;371:42-9.

21. Vriezinga $S L$, Auricchio $R$, Bravi E, et al. Randomized feeding intervention in infants at high risk for celiac disease. N Engl J Med. 2014;371:1304-15.

22. Mazzilli MC, Ferrante $P$, Mariani $P$, et al. A study of Italian pediatric celiac disease patients confirms that the primary HLA association is to the DQ (a1* 0501, $\beta 1 * 0201$ ) heterodimer. Human Immunol. 1992;33:133-9.

23. Dieli-Crimi $R$, Cénit MC, Núñez $C$. The genetics of celiac disease: a comprehensive review of clinical implications. J Autoimmun. 2015;64: 26-41.

24. Silano M, Vincentini $O$, De Vincenzi M. Toxic, immunostimulatory and antagonist gluten peptides in celiac disease. Curr Med Chem. 2009;16: 1489-98.

25. Shan L, Molberg O, Parrot I, et al. Structural basis for gluten intolerance in celiac sprue. Science. 2002;297:2275-9.

26. Jelinkova L, Tuckova L, Cinova J, et al. Gliadin stimulates human monocytes to production of IL-8 and TNF-alpha through a mechanism involving NFkappaB. FEBS Lett. 2004;571:81-5.

27. Lammers KM, Khandelwal S, Chaudhry F, et al. Identification of a novel immunomodulatory gliadin peptide that causes interleukin-8 release in a chemokine receptor CXCR3-dependent manner only in patients with coeliac disease. Immunology. 2011;132:432-40.

28. Picarelli A, Di Tola M, Sabbatella L, et al. 31-43 amino acid sequence of the alpha-gliadin induces anti-endomysial antibody production during in vitro challenge. Scand J Gastroenterol. 1999;34:1099-102.

29. Clemente MG, De Virgiliis S, Kang JS, et al. Early effects of gliadin on enterocyte intracellular signalling involved in intestinal barrier function. Gut. 2003;52:218-23.

30. Sander GR, Cummins AG, Henshall T, Powell BC. Rapid disruption of intestinal barrier function by gliadin involves altered expression of apical junctional proteins. FEBS Lett. 2005;579:4851-5.

31. Wang W, Uzzau S, Goldblum SE, Fasano A. Human zonulin, a potential modulator of intestinal tight junctions. J Cell Sci. 2000;113:4435-40.

32. Fasano A, Not T, Wang W, et al. Zonulin, a newly discovered modulator of intestinal permeability, and its expression in coeliac disease. Lancet. 2000; 355:1518-9.

33. Tripathi A, Lammers KM, Goldblum S, et al. Identification of human zonulin, a physiological modulator of tight junctions, as prehaptoglobin-2. Proc Natl Acad Sci U S A. 2009;106:16799-804.

34. El Asmar R, Panigrahi P, Bamford P, et al. Host-dependent zonulin secretion causes the impairment of the small intestine barrier function after bacterial exposure. Gastroenterology. 2002;123:1607-15.

35. Smecuol E, Sugai E, Niveloni S, et al. Permeability, zonulin production, and enteropathy in dermatitis herpetiformis. Clin Gastroenterol Hepatol. 2005;3: 335-41.

36. Sapone A, de Magistris L, Pietzak M, et al. Zonulin upregulation is associated with increased gut permeability in subjects with type 1 diabetes and their relatives. Diabetes. 2006;55:1443-9.
37. Simpson M, Mojibian M, Barriga K, et al. An exploration of Glo-3A antibody levels in children at increased risk for type 1 diabetes mellitus. Pediatr Diabetes. 2009;10:563-72.

38. Duerksen DR, Wilhelm-Boyles $C$, Veitch $R$, et al. A comparison of antibody testing, permeability testing, and zonulin levels with small-bowel biopsy in celiac disease patients on a gluten-free diet. Dig Dis Sci. 2010;55:1026-31.

39. Drago S, El Asmar R, Di Pierro M, et al. Gliadin, zonulin and gut permeability: effects on celiac and non-celiac intestinal mucosa and intestinal cell lines. Scand J Gastroenterol. 2006:41:408-19.

40. Hollon J, Puppa EL, Greenwald B, et al. Effect of gliadin on permeability of intestinal biopsy explants from celiac disease patients and patients with non-celiac gluten sensitivity. Nutrients. 2015;7:1565-76.

41. Paterson BM, Lammers KM, Arrieta MC, et al. The safety, tolerance, pharmacokinetic and pharmacodynamic effects of single doses of AT-1001 in coeliac disease subjects: a proof of concept study. Aliment Pharmacol Ther. 2007;26:757-66.

42. Thomas KE, Sapone A, Fasano A, Vogel SN. Gliadin stimulation of murine macrophage inflammatory gene expression and intestinal permeability are MyD88-dependent: role of the innate immune response in celiac disease. J Immunol. 2006;176:2512-21.

43. Lammers KM, Lu R, Brownley J, et al. Gliadin induces an increase in intestinal permeability and zonulin release by binding to the chemokine receptor CXCR3. Gastroenterology. 2008;135:194-204.

44. Monsuur AJ, de Bakker PI, Alizadeh BZ, et al. Myosin IXB variant increases the risk of celiac disease and points toward a primary intestinal barrier defect. Nat Genet. 2005:37:1341-4.

45. Loeff T, Araya M, Pérez-Bravo F. Frequency of MYO9B polymorphisms in celiac patients and controls. Rev Esp Enferm Dig. 2012;104:566-71.

46. Wapenaar MC, Monsuur AJ, van Bodegraven AA, et al. Associations with tight junction genes PARD3 and MAGI2 in Dutch patients point to a common barrier defect for coeliac disease and ulcerative colitis. Gut. 2008; 57:463-7.

47. Schumann M, Richter JF, Wedell I, et al. Mechanisms of epithelial translocation of the alpha(2)-gliadin-33mer in coeliac sprue. Gut. 2008;57: 747-54.

48. Moreno ML, Cebolla Á, Muñoz-Suano A, et al. Detection of gluten immunogenic peptides in the urine of patients with coeliac disease reveals transgressions in the gluten-free diet and incomplete mucosal healing. Gut. 2017;66:250-7.

49. Matysiak-Budnik T, Moura IC, Arcos-Fajardo M, et al. Secretory IgA mediates retrotranscytosis of intact gliadin peptides via the transferrin receptor in celiac disease. J Exp Med. 2008;205:143-54.

50. Kim SM, Mayassi T, Jabri B. Innate immunity: actuating the gears of celiac disease pathogenesis. Best Pract Res Clin Gastroenterol. 2015;29:425-35.

51. Junker Y, Zeissig S, Kim SJ, et al. Wheat amylase trypsin inhibitors drive intestinal inflammation via activation of toll-like receptor 4. J Exp Med. 2012; 209:2395-408

52. Barone MV, Troncone R, Auricchio S. Gliadin peptides as triggers of the proliferative and stress/innate immune response of the celiac small intestinal mucosa. Int J Mol Sci. 2014;15:20518-37.

53. Cinova J, Palova-Jelinkova L, Smythies LE, et al. Gliadin peptides activate blood monocytes from patients with celiac disease. J Clin Immunol. 2007; 27:201-9.

54. Lammers KM, Chieppa M, Liu L, et al. Gliadin induces neutrophil migration via engagement of the formyl peptide receptor, FPR1. PLoS One. 2015;10: e0138338.

55. Stamnaes J, Sollid LM. Celiac disease: autoimmunity in response to food antigen. Semin Immunol. 2015;27:343-52.

56. Tang F, Chen Z, Ciszewski C, et al. Cytosolic PLA2 is required for CTLmediated immunopathology of celiac disease via NKG2D and IL-15. J Exp Med. 2009;206:707-19.

57. Tjon JM, van Bergen J, Koning F. Celiac disease: how complicated can it get? Immunogenetics. 2010;62:641-51.

58. Pagliari $\mathrm{D}$, Urgesi $\mathrm{R}$, Frosali $\mathrm{S}$, et al. The interaction among microbiota, immunity, and genetic and dietary factors is the condicio sine qua non celiac disease can develop. J Immunol Res. 2015;2015:123653.

59. Hüe S, Mention JJ, Monteiro RC, et al. A direct role for NKG2D/MICA interaction in villous atrophy during celiac disease. Immunity. 2004;21:367-77.

60. Senger S, Sapone A, Fiorentino MR, et al. Celiac disease histopathology recapitulates hedgehog downregulation, consistent with wound healing processes activation. PLoS One. 2015;10:e0144634. 
61. Ju JM, Marietta EV, Murray JA. Generating transgenic mouse models for studying celiac disease. Methods Mol Biol. 2015;1326:23-33.

62. Schumann M, Siegmund B, Schulzke JD, Fromm M. Celiac disease: role of the epithelial barrier. Cell Mol Gastroenterol Hepatol. 2017;3:150-62.

63. Olivares M, Benítez-Páez A, de Palma G, et al. Increased prevalence of pathogenic bacteria in the gut microbiota of infants at risk of developing celiac disease: the PROFICEL study. Gut Microbes. 2018;9:551-8.

64. Chander AM, Yadav $\mathrm{H}$, Jain $\mathrm{S}$, et al. Cross-talk between gluten, intestinal microbiota and intestinal mucosa in celiac disease: recent advances and basis of autoimmunity. Front Microbiol. 2018;9:2597.

65. Sellitto M, Bai G, Serena G, et al. Proof of concept of microbiomemetabolome analysis and delayed gluten exposure on celiac disease autoimmunity in genetically at-risk infants. PLoS One. 2012;7:e33387.

66. Olivares M, Neef A, Castillejo G, et al. The HLA-DQ2 genotype selects for early intestinal microbiota composition in infants at high risk of developing coeliac disease. Gut. 2015;64:406-17.

67. Choung RS, Ditah IC, Nadeau AM, et al. Trends and racial/ethnic disparities in gluten-sensitive problems in the United States: findings from the National Health and nutrition examination surveys from 1988 to 2012. Am J Gastroenterol. 2015;110:455-61.

68. Fasano A. Celiac disease: how to handle a clinical chamaleon. N Engl J Med. 2003;348:2568-70.

69. Ludvigsson JF, Leffler DA, Bai JC, et al. The Oslo definitions for coeliac disease and related terms. Gut. 2013;6:43-52.

70. Leonard MM, Sapone A, Catassi C, Fasano A. Celiac disease and nonceliac gluten sensitivity: a review. JAMA. 2017;318:647-56.

71. Vivas S, Ruiz de Morales JM, Fernandez M, et al. Age-related clinical, serological, and histopathological features of celiac disease. Am J Gastroenterol. 2008;103:2360-5.

72. Reilly NR, Aguilar K, Hassid BG, et al. Celiac disease in normal-weight and overweight children: clinical features and growth outcomes following a gluten-free diet. J Pediatr Gastroenterol Nutr. 2011;53:528-31.

73. Baydoun A, Maakaron JE, Halawi H, et al. Hematological manifestations of celiac disease. Scand J Gastroenterol. 2012:47:1401-11.

74. Kamycheva E, Goto T, Camargo CA Jr. Celiac disease is associated with reduced bone mineral density and increased FRAX scores in the US National Health and nutrition examination survey. Osteoporos Int. 2017;28:781-90.

75. Krzywicka B, Herman K, Kowalczyk-Zając M, Pytrus T. Celiac disease and its impact on the oral health status - review of the literature. Adv Clin Exp Med. 2014;23:675-81.

76. Volta U, De Franceschi L, Lari F, et al. Coeliac disease hidden by cryptogenic hypertransaminasaemia. Lancet. 1998;352:26-9.

77. Volta U, Caio G, Tovoli F, De Giorgio R. Gut-liver axis: an immune link between celiac disease and primary biliary cirrhosis. Expert Rev Gastroenterol Hepatol. 2013;7:253-61.

78. Volta U, Tovoli F, Caio G. Clinical and immunological features of celiac disease in patients with type 1 diabetes mellitus. Expert Rev Gastroenterol Hepatol. 2011:5:479-87.

79. Caio G, De Giorgio R, Venturi A, et al. Clinical and immunological relevance of anti-neuronal antibodies in celiac disease with neurological manifestations. Gastroenterol Hepatol Bed Bench. 2015:8:146-52.

80. Saccone G, Berghella V, Sarno L, et al. Celiac disease and obstetric complications: a systematic review and metanalysis. Am J Obstet Gynecol. 2016;214:225-34

81. Farthing MJG, Edwards CRW, Rees LH, Dawson AM. Male gonadal function in coeliac disease: sexual dysfunction, infertility and semen quality. Gut. 1982;23:608-14.

82. Leffler DA, Green PH, Fasano A. Extraintestinal manifestations of coeliac disease. Nat Rev Gastroenterol Hepatol. 2015;12:561-71.

83. Gale L, Wimalaratna H, Brotodiharjo A, Duggan JM. Down's syndrome is strongly associated with coeliac disease. Gut. 1997;40:492-6.

84. Bonamico M, Pasquino AM, Mariani P, et al. Prevalence and clinical picture of celiac disease in turner syndrome. J Clin Endocrinol Metab. 2002;87:5495-8.

85. Giannotti A, Tiberio G, Castro M, et al. Coeliac disease in Williams syndrome. J Med Genet. 2001;38:767-8.

86. Caio G, De Giorgio R, Ursini F, et al. Prevalence of celiac disease serological markers in a cohort of Italian rheumatological patients. Gastroenterol Hepatol Bed Bench. 2018;11:244-9.

87. Volta U, De Franceschi L, Molinaro N, et al. Frequency and significance of anti-gliadin and anti-endomysial antibodies in autoimmune hepatitis. Dig Dis Sci. 1998;43:2190-5.
88. Volta U, Rodrigo L, Granito A, et al. Celiac disease in autoimmune cholestatic liver disorders. Am J Gastroenterol. 2002;97:2609-13.

89. Volta U, Bardazzi F, Zauli D, et al. Serological screening for coeliac disease in vitiligo and alopecia areata. Br J Dermatol. 1997;136:801-2.

90. Oleary $\mathrm{C}$, Walsh $\mathrm{CH}$, Wieneke $\mathrm{P}$, et al. Coeliac disease and autoimmune Addison's disease: a clinical pitfall. QJM. 2002;95:79-82.

91. Cataldo F, Marino V, Ventura A, et al. Prevalence and clinical features of selective immunoglobulin a deficiency in coeliac disease: an Italian multicentre study. Gut. 1998;42:362-5.

92. Curione M, Barbato M, De Biase L, et al. Prevalence of coeliac disease in idiopathic dilated cardiomiopathy. Lancet. 1999;354:222-3.

93. Caio G, De Giorgio R, Volta U. Coeliac disease and dermatitis herpetiformis. Lancet. 2018:392:916-7.

94. Volta U, Caio G, Boschetti E, et al. Seronegative celiac disease: shedding light on an obscure clinical entity. Dig Liver Dis. 2016;48:1018-22.

95. Mooney PD, Evans KE, Singh S, Sanders DS. Treatment failure in coeliac disease: a practical guide to investigation and treatment of non-responsive and refractory coeliac disease. J Gastrointest Liver Dis. 2012;21:197-203.

96. Volta U, Granito A, Fiorini E, et al. Usefulness of antibodies to deamidated gliadin peptides in celiac disease diagnosis and follow-up. Dig Dis Sci. 2008;853:1582-8.

97. Volta U, Tovoli F, Piscaglia M, et al. Old and new serological test for celiac disease screening. Exp Rev Gatroenterol Hepatol. 2010;4:31-5.

98. Caio G, Volta U. Coeliac disease: changing diagnostic criteria? Gastroenterol Hepatol Bed Bench. 2012;5:119-22.

99. Husby S, Koletzko S, Korponay-Szabó IR, et al. European Society for Pediatric Gastroenterology, hepatology, and nutrition guidelines for the diagnosis of coeliac disease. J Pediatr Gastroenterol Nutr. 2012;54:136-60.

100. Werkstetter KJ, Korponay-Szabó IR, Popp A, et al. Accuracy in diagnosis of celiac disease without biopsies in clinical practice. Gastroenterology. 2017; 153:924-35.

101. Egner W, Shrimpton A, Sargur R, et al. ESPGHAN guidance on coeliac disease 2012: multiples of ULN for decision making do not harmonise assay performance across centres. J Pediatr Gastroenterol Nutr. 2012;55:733-5.

102. Fuchs V, Kurppa K, Huhtala H, et al. Serology-based criteria for adult coeliac disease have excellent accuracy across the range of pre-test probabilities. Aliment Pharmacol Ther. 2019;49:277-84.

103. Catassi C, Fasano A. Celiac disease diagnosis: simple rules are better than complicated algorithms. Am J Med. 2010;123:691-3.

104. Kostopoulou O, Devereaux-Walsh C, Delaney BC. Missing celiac disease in family medicine: the importance of hypothesis generation. Med Decis Mak. 2009;29:282-90

105. Zanchetta MB, Longobardi V, Bai JC. Bone and celiac disease. Curr Osteoporos Rep. 2016;14:43-8.

106. Corazza GR, Zoli G, Di Sabatino A, et al. A reassessment of splenic hypofunction in celiac disease. Am J Gastroenterol. 1999;94:391-7.

107. Caraceni P, Benazzi B, Caio G, et al. Hyposplenism as a cause of pneumococcal meningoencephalitis in an adult patient with celiac disease. Ital J Med. 2011;5:124-7

108. Di Sabatino A, Rosado MM, Cazzola P, et al. Splenic hypofunction and the spectrum of autoimmune and malignant complications in celiac disease. Clin Gastroenterol Hepatol. 2006:4:179-86.

109. Caio G, Riegler G, Patturelli M, et al. Pathophysiology of non-celiac gluten sensitivity: where are we now? Minerva Gastroenterol Dietol. 2017:63:16-21.

110. Villalta D, Tonutti E, Prause C, et al. IgG antibodies against deamidated gliadin peptides for diagnosis of celiac disease in patients with $\lg A$ deficiency. Clin Chem. 2010;56:464-8.

111. Volta U, Molinaro N, De Franceschi $\mathrm{L}$, et al. IgA anti-endomysial antibodies on human umbilical cord tissue for celiac disease screening: save both money and monkeys. Dig Dis Sci. 1995:40:1902-5.

112. Stern M. Comparative evaluation of serologic tests for celiac disease: a European initiative toward standardization. J Pediatr Gastroenterol Nutr. 2000;31:513-9.

113. Salardi S, Volta U, Zucchini S, et al. Prevalence of celiac disease in children with type 1 diabetes mellitus increased in the mid-1990s: an 18-year longitudinal study based on anti-endomysial antibodies. J Pediatr Gastroenterol Nutr. 2008;46:612-4.

114. Zucchini L, Giusti D, Gatouillat G, et al. Interpretation of serological tests in the diagnosis of celiac disease: anti-deamidated gliadin peptide antibodies revisited. Autoimmunity. 2016:49:414-20.

115. Amarri S, Alvisi P, De Giorgio R, et al. Antibodies to deamidated gliadin peptides: an accurate predictor of coeliac disease in infancy. J Clin Immunol. 2013;33:1027-30. 
116. Dipper CR, Maitra S, Thomas R, et al. Anti-tissue transglutaminase antibodies in the follow-up of adult coeliac disease. Aliment Parmacol Ther. 2009;30:236-44.

117. Choung RS, Khaleghi Rostamkolaei S, Ju JM, et al. Synthetic neoepitopes of the transglutaminase-deamidated gliadin complex as biomarkers for diagnosing and monitoring celiac disease. Gastroenterology. 2019;156:582-91.

118. Leonard MM, Weir DC, DeGroote M, et al. Value of IgA tTG in predicting mucosal recovery in children with celiac disease on a gluten-free diet. J Pediatr Gastroenterol Nutr. 2017;64:286-91.

119. Leonard MM, Fasano A. Zero, one, or two endoscopies to diagnose and monitor pediatric celiac disease? The jury is still out. J Pediatr Gastroenterol Nutr. 2017:65:270-1.

120. Oberhüber G, Granditsch G, Vogelsang $H$. The histopathology of celiac disease: time for a standardized report scheme for pathologists. Eur J Gastroenterol Hepatol. 1999;11:1185-94.

121. Corazza GR, Villanacci V. Coeliac disease: some considerations on the histological diagnosis. J Clin Pathol. 2005;58:573-4.

122. Oxentenko AS, Murray JA. Celiac disease: ten things that every gastroenterologist should know. Clin Gastroenterol Hepatol. 2015;13:1396-404.

123. Villanacci V, Ceppa P, Tavani E, et al. Coeliac disease: the histology report. Dig Liver Dis. 2011;43:385-95.

124. Rostami-Nejad M, Villanacci V, Hogg-Kollars S, et al. Endoscopic and histological pitfalls in the diagnosis of celiac disease: a multicentre study assessing the current practice. Rev Esp Enferm Dig. 2013;105:326-33.

125. Brown I, Mino-Kenudson M, Deshpande V, Lauwers GY. Intraepithelial lymphocytosis in architecturally preserved proximal small intestinal mucosa. Arch Pathol Lab Med. 2006;130:1020-5.

126. Biagi F, Bianchi PI, Campanella J, et al. The prevalence and the causes of minimal intestinal lesions in patients complaining of symptoms suggestive of enteropathy. A follow-up study. J Clin Pathol. 2008;61:1116-8.

127. Kakar S, Nehra V, Murray JA, et al. Significance of intraepithelial lymphocytosis in small bowel biopsy samples with normal mucosa architecture. Am J Gastroenterol. 2003;98:2027-33.

128. Upton MP. "Give us this day our daily bread". Evolving concepts in celiac sprue. Arch Pathol Lab Med. 2008;132:1594-9.

129. Fernández-Bañares F, Carrasco A, García-Puig R, et al. Intestinal intraepithelial lymphocyte cytometric pattern is more accurate than subepithelial deposits of anti-tissue transglutaminase IgA for the diagnosis of celiac disease in lymphocytic enteritis. PLoS One. 2014;9:e101249.

130. Rostami K, Marsh MN, Johnson MW, et al. ROC-king onwards: intraepithelial lymphocyte counts, distribution \& role in coeliac disease mucosal interpretation. Gut. 2017;66:2080-6.

131. Marsh MN, Rostami K. What is a normal intestinal mucosa? Gastroenterology. 2016;151:784-8.

132. Marsh MN, Johnson WM, Rostami K. Mucosal histopathology in celiac disease: a rebuttal of Oberhuber's sub-division of Marsh III. Gastroenterol Hepatol Bed Bench. 2015;8:99-109.

133. Rubio-Tapia A, Hill ID, Kelly CP, et al. ACG clinical guidelines: diagnosis and management of celiac disease. Am J Gastroenterol. 2013;108:656-76.

134. Volta U, Villanacci V. Celiac disease: diagnostic criteria in progress. Cell Mol Immunol. 2011;8:96-102.

135. Volta U, Caio G, Giancola F, et al. Features and progression of potential celiac disease in adults. Clin Gastroenterol Hepatol. 2016;14:686-93.

136. Kurppa $K$, Collin P, Viljamaa M, et al. Diagnosing mild enteropathy celiac disease: a randomized, controlled clinical study. Gastroenterology. 2009;136:816-23.

137. Tosco A, Salvati VM, Auricchio R, et al. Natural history of potential celiac disease in children. Clin Gastroenterol Hepatol. 2011;9:320-5.

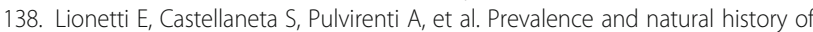
potential celiac disease in at-family-risk infants prospectively investigated from birth. J Pediatr. 2012;161:908-14.

139. Zanini B, Caselani F, Magni A, et al. Celiac disease with mild enteropathy is not mild disease. Clin Gastroenterol Hepatol. 2013;11:253-8.

140. Biagi F, Trotta L, Alfano C, et al. Prevalence and natural history of potential celiac disease in adult patients. Scand J Gastroenterol. 2013;48:537-42.

141. Auricchio R, Tosco A, Piccolo E, et al. Potential celiac children: 9-year followup on a gluten-containing diet. Am J Gastroenterol. 2014;109:913-21.

142. Kurppa $K$, Collin $P$, Lindfors $K$, et al. Spontaneous negative seroconversion of endomysial antibodies does not exclude subsequent celiac disease. J Pediatr Gastroenterol Nutr. 2011;53:576-9.

143. Rostami K, Kerckhaert J, Tiemessen R, et al. Sensitivity of antiendomysium and antigliadin antibodies in untreated celiac disease: disappointing in clinical practice. Am J Gastroenterol. 1999;94:888-94.
144. Shah VH, Rotterdam $H$, Kotler DP, et al. All that scallops is not celiac disease. Gastrointest Endosc. 2000;51:717-20.

145. Greenson JK. The biopsy pathology of non-coeliac enteropathy. Histopathology. 2015;66:29-36.

146. De Gaetani M, Tennyson CA, Lebwohl B, et al. Villous atrophy and negative celiac serology: a diagnostic and therapeutic dilemma. Am J Gastroenterol. 2013;108:647-53.

147. Aziz I, Peerally MF, Barnes JH, et al. The clinical and phenotypical assessment of seronegative villous atrophy; a prospective UK centre experience evaluating 200 adult cases over a 15-year period (2000-2015). Gut. 2017;66:1563-72.

148. Dewar DH, Donnelly SC, McLaughlin SD, et al. Celiac disease: management of persistent symptoms in patients on a gluten-free diet. World J Gastroenterol. 2012;18:1348-56.

149. Rubio-Tapia A, Ludvigsson JF, Choung RS, et al. Increased mortality among men aged 50 years old or above with elevated lgA anti-transglutaminase antibodies: NHANES III. BMC Gastroenterol. 2016;16:136.

150. Biagi F, Gobbi P, Marchese A, et al. Low incidence but poor prognosis of complicated coeliac disease: a retrospective multicentre study. Dig Liver Dis. 2014;46:227-30

151. Al-Toma A, Goerres MS, Meijer JW, et al. Human leukocyte antigen-DQ2 homozygosity and the development of refractory celiac disease and enteropathy-associated T-cell lymphoma. Clin Gastroenterol Hepatol. 2006;4: 315-9.

152. Di Sabatino A, Brunetti L, Carnevale Maffè $G$, et al. Is it worth investigating splenic function in patients with celiac disease? World J Gastroenterol. 2013 19:2313-8.

153. Roshan B, Leffler DA, Jamma S, et al. The incidence and clinical spectrum of refractory celiac disease in a north American referral center. Am J Gastroenterol. 2011;106:923-8.

154. Malamut G, Afchain P, Verkarre V, et al. Presentation and long-term followup of refractory celiac disease: comparison of type I with type II. Gastroenterology. 2009;136:81-90.

155. Nasr I, Nasr I, Campling H, Ciclitira PJ. Approach to patients with refractory coeliac disease. F1000Res. 2016;5. https://doi.org/10.12688/f1000research.9051.1.

156. Nasr I, Nasr I, Beyers C, et al. Recognising and managing refractory coeliac disease: a tertiary Centre experience. Nutrients. 2015;7:9896-907.

157. Williams MJ, Sutherland DH, Clark CG. Lymphosarcoma of the small intestine with a malabsorption syndrome and pneumatosis intestinalis. Report of a case with peroral jejunal biopsy. Gastroenterology. 1963;45: 550 e7.

158. Silano M, Volta U, Mecchia AM, et al. Delayed diagnosis of coeliac disease increases cancer risk. BMC Gastroenterol. 2007:7:8.

159. Malamut G, Cellier C. Complications of coeliac disease. Best Pract Res Clin Gastroenterol. 2015:29:451-8.

160. Cheminant M, Bruneau J, Malamut $G$, et al. NKp46 is a diagnostic biomarker and may be a therapeutic target in gastrointestinal T-cell lymphoproliferative diseases: a CELAC study. Gut. 2018. https://doi.org/1 0.1136/gutjnl-2018-317371

161. Ilus T, Kaukinen $K$, Virta $\sqcup$, et al. Incidence of malignancies in diagnosed celiac patients: a population-based estimate. Am J Gastroenterol. 2014;109: 1471-7.

162. Caio G, Volta U, Ursini F, et al. Small bowel adenocarcinoma as a complication of celiac disease: clinical and diagnostic features. BMC Gastroenterol. 2019;19:45.

163. Catassi C, Copparoni R, Corazza GR, et al. Protocollo per la diagnosi ed il follow-up della malattia celiaca. Gazzetta Ufficiale della Repubblica Italiana, Serie Generale n.191 del 19/08/2015, pp. 148-58.

164. Tortora R, Capone P, De Stefano G, et al. Metabolic syndrome in patients with coeliac disease on a gluten-free diet. Aliment Pharmacol Ther. 2015:41: 352-9.

165. Reilly NR, Lebwohl B, Hultcrantz R, et al. Increased risk of non-alcoholic fatty liver disease after diagnosis of celiac disease. J Hepatol. 2015;62:1405-11.

166. Laurikka P, Salmi T, Collin P, et al. Gastrointestinal symptoms in celiac disease patients on a long-term gluten-free diet. Nutrients. 2016;14:8.

167. Thompson T. Folate, iron, and dietary fiber contents of the gluten-free diet. J Am Diet Assoc. 2000;100:1389-96

168. Carroccio A, Ambrosiano G, Di Prima L, et al. Clinical symptoms in celiac patients on a gluten-free diet. Scand J Gastroenterol. 2008;43:1315-21.

169. Valitutti F, Trovato CM, Montuori M, Cucchiara S. Pediatric celiac disease: follow-up in the spotlight. Adv Nutr. 2017:8:356-61. 
170. Mubarak A, Oudshoorn JH, Kneepkens CM, et al. A child with refractory coeliac disease. J Pediatr Gastroenterol Nutr. 2011;53:216-8.

171. West J, Logan RF, Card TR, et al. Risk of vascular disease in adults with diagnosed coeliac disease: a population-based study. Aliment Pharmacol Ther. 2004;20:73-9.

172. Hallert C, Grant C, Grehn S, et al. Evidence of poor vitamin status in coeliac patients on a gluten-free diet for 10 years. Aliment Pharmacol Ther. 2002;16: 1333-9.

173. Midhagen G, Hallert C. High rate of gastrointestinal symptoms in celiac patients living on a gluten-free diet: controlled study. Am J Gastroenterol. 2003:98:2023-6.

174. Roos S, Kärner A, Hallert C. Psychological well-being of adult coeliac patients treated for 10 years. Dig Liver Dis. 2006;38:177-80.

175. Aziz I, Evans KE, Papageorgiou V, Sanders DS. Are patients with coeliac disease seeking alternative therapies to a gluten-free diet? J Gastrointestin Liver Dis. 2011;20:27-31.

176. McCarville JL, Caminero A, Verdu EF. Pharmacological approaches in celiac disease. Curr Opin Pharmacol. 2015;25:7-12.

177. Leffler DA, Kelly CP, Green PH, et al. Larazotide acetate for persistent symptoms of celiac disease despite a gluten-free diet: a randomized controlled trial. Gastroenterology. 2015;148:1311-9.

178. Lähdeaho ML, Kaukinen K, Laurila K, et al. Glutenase ALV003 attenuates gluten-induced mucosal injury in patients with celiac disease. Gastroenterology. 2014;146:1649-58.

179. Gottlieb K, Dawson J, Hussain F, Murray JA. Development of drugs for celiac disease: review of endpoints for phase 2 and 3 trials. Gastroenterol Rep. 2015;3:91-102

180. Murray JA, Kelly CP, Green PHR, et al. No difference between latiglutenase and placebo in reducing villous atrophy or improving symptoms in patients with symptomatic celiac disease. Gastroenterology. 2017;152:787-98.

181. Anderson RP, Jabri B. Vaccine against autoimmune disease: antigen-specific immunotherapy. Curr Opin Immunol. 2013;25:410-7.

182. Lionetti E, Castellaneta S, Francavilla R, et al. Mode of delivery and risk of celiac disease: risk of celiac disease and age at gluten introduction cohort study. J Pediatr. 2017;184:81-6.

183. Koletzko S, Lee HS, Beyerlein A, et al. Cesarean section on the risk of celiac disease in the offspring: the teddy study. J Pediatr Gastroenterol Nutr. 2018; 66:417-24.

184. Dydensborg Sander S, Hansen AV, Størdal K, et al. Mode of delivery is not associated with celiac disease. Clin Epidemiol. 2018;10:323-32.

185. Silvester JA, Leffler DA. Is autoimmunity infectious? The effect of gastrointestinal viral infections and vaccination on risk of celiac disease autoimmunity. Clin Gastroenterol Hepatol. 2017;15:703-5.

186. Leonard MM, Camhi S, Huedo-Medina TD, Fasano A. Celiac disease genomic, environmental, microbiome, and Metabolomic (CDGEMM) study design: approach to the future of personalized prevention of celiac disease. Nutrients. 2015;7:9325-36.

187. Hujoel IA, Van Dyke CT, Brantner T, et al. Natural history and clinical detection of undiagnosed coeliac disease in a north American community Aliment Pharmacol Ther. 2018;47:1358-66.

\section{Publisher's Note}

Springer Nature remains neutral with regard to jurisdictional claims in published maps and institutional affiliations.

Ready to submit your research? Choose BMC and benefit from:

- fast, convenient online submission

- thorough peer review by experienced researchers in your field

- rapid publication on acceptance

- support for research data, including large and complex data types

- gold Open Access which fosters wider collaboration and increased citations

- maximum visibility for your research: over $100 \mathrm{M}$ website views per year

At BMC, research is always in progress.

Learn more biomedcentral.com/submissions 